\title{
Extracorporeal Membrane Oxygenation for Severe Pediatric Respiratory Failure
}

\author{
John C Lin MD
}

\author{
Introduction \\ ECMO Basics \\ Indications \\ Pediatric ARDS \\ Bridge to Lung Transplantation \\ Other \\ ECMO Transport \\ Ventilator Management During ECMO \\ Criteria for Separation From ECMO \\ Developing Techniques \\ High-Frequency Percussive Ventilation \\ Pumpless Extracorporeal Support \\ Summary
}

\begin{abstract}
Extracorporeal membrane oxygenation (ECMO) was developed initially in the 1960s to support refractory respiratory failure in addition to the cardiac support inherent in a venoarterial bypass circuit. Early successes occurred predominantly in the neonatal population with subsequent randomized controlled trials and comprehensive reviews concluding therapeutic efficacy for ECMO in neonatal respiratory failure. In contrast, the evidence supporting ECMO for respiratory failure in children is less definitive. However, although pediatric randomized controlled trials have not been completed, sufficient evidence in support of ECMO as a beneficial therapy for pediatric respiratory failure exists. The acceptance of clinical utility and benefit from ECMO for pediatric ARDS and the trend toward increasing venovenous ECMO use have led to its inclusion in the Pediatric Acute Lung Injury Consensus Conference as a strongly agreed upon recommendation for severe pediatric ARDS. However, the Pediatric Acute Lung Injury Consensus Conference recommendations supporting the use of ECMO for pediatric ARDS highlight the lack of evidence-based selection criteria when determining ECMO candidacy in pediatric patients with ARDS. Ultimately, decisions to proceed with ECMO and the concomitant risk of potential life-threatening complications must consider multiple factors that balance potential risks and likelihood of benefit, pre-morbid conditions and impact on potential post-ECMO quality of life, candidacy for lung transplantation, and patient and family goals of care. This review will discuss ECMO for the support of pediatric respiratory failure, ventilator management during ECMO, considerations impacting timing of decannulation, and developing techniques. Key words: pediatrics; pediatric ARDS; respiratory failure; ECMO. [Respir Care 2017;62(6):732-750. (C) 2017 Daedalus Enterprises]
\end{abstract}




\section{ECMO for Severe Pediatric Respiratory Failure}

\section{Introduction}

Extracorporeal membrane oxygenation (ECMO) was developed initially in the 1960 s to support refractory respiratory failure in addition to the cardiac support inherent in a venoarterial bypass circuit. The first human application was reported in 1972 and involved successful treatment of a 24-y-old with postoperative refractory respiratory failure following traumatic thoracic aortic injury. ${ }^{1}$ Following a series of case reports and small case series over the next $6 \mathrm{y}$, Hill et $\mathrm{al}^{2}$ summarized in 1978 the international experience with ECMO for acute respiratory failure and reported 38 survivors in 230 cases that included 8 of 38 pediatric (20\%) and 29 of 192 adult (15\%) ECMO survivors. Despite these initial discouraging outcomes, the ongoing high mortality of those patients for whom ECMO was a last resort continued to drive advances and refinement in technical approach, equipment technology, patient selection, prevention and management of complications, and team composition and training. These advances have resulted in steady improvement in survival to hospital discharge.

Early successes occurred predominantly in the neonatal population. ${ }^{3,4}$ In the decades since the 1960s, 3 neonatal randomized controlled trials have demonstrated significant improvement in mortality in pulmonary hypertension specifically and respiratory failure in general with subsequent follow-up studies demonstrating continued benefit in longterm outcomes. ${ }^{5-9}$ A Cochrane review in 2008 concluded that ECMO in mature infants with potentially reversible respiratory failure significantly improved survival. ${ }^{10}$ Subsequent single-center case series of neonatal respiratory ECMO demonstrated stable survival rates between 67 and 91.1\% from 1987 to 2006 across the range of causes of respiratory failure. ${ }^{11,12}$ Of the causes of respiratory failure, congenital diaphragmatic hernia carried markedly worse outcomes and longer time receiving ECMO compared with all other neonatal respiratory diagnoses: meconium aspiration syndrome, persistent pulmonary hypertension, respiratory distress syndrome, sepsis, pneumonia, or air-leak syndrome. ${ }^{13}$

Dr Lin is affiliated with Washington University School of Medicine, St Louis, Missouri.

Dr Lin has disclosed no conflicts of interest.

Dr Lin presented a version of this paper at the 55th RESPIRATORY CARE Journal Conference, "Pediatric Respiratory Care," held June 10-11, 2016, in St Petersburg, Florida.

Correspondence: John C Lin MD, Washington University School of Medicine, 1 Children's Place, Campus Box 8116, St. Louis, MO 63110-1010. E-mail: lin_jo@kids.wustl.edu.

DOI: $10.4187 /$ respcare. 05338
In contrast, the evidence supporting ECMO for respiratory failure in adults and children is less definitive. Two adult randomized controlled trials showed no mortality benefit from ECMO, ${ }^{14,15}$ and the most recent adult CESAR trial appeared to demonstrate the salutary impact of referral to an ECMO center rather than actual use of ECMO. ${ }^{16,17}$ The evidence for ECMO use in pediatric respiratory failure lacks any randomized trials. A retrospective cohort analysis of 29 ECMO subjects compared with 53 non-ECMO matched controls found a reduction in mortality from $47 \%$ to $26 \%$ in the ECMO cohort. In particular, those subjects with a mortality risk of $50-75 \%$ based on admission pediatric risk of mortality score and oxygenation index (OI) derived a survival benefit from ECMO use, with only $29 \%$ observed mortality compared with $71 \%$ mortality in the non-ECMO-treated subjects. ${ }^{18}$ An attempted randomized trial for non-neonatal pediatric ECMO was aborted due to an inability to achieve enrollment goals and lower mortality than expected in the nonECMO group. ${ }^{19}$ Nevertheless, ECMO remains a widely utilized therapy for refractory pediatric respiratory failure, with overall survival comparable with neonatal cases. The most recent Extracorporeal Life Support Organization (ELSO) registry from 1990 to July 2016 contains a cumulative 7,710 pediatric respiratory ECMO cases, of whom $4,439(57.6 \%)$ survived to hospital discharge or transfer. ${ }^{13}$ More recently, in the $6 \mathrm{y}$ from 2010 to 2015, the ELSO registry reported 2,689 cases (448 cases annually) with $61 \%$ survival to discharge and an increasing trend toward venovenous (VV) and dual-lumen VV approaches in $>50 \%$ of cases in 2015.13 The acceptance of clinical utility and benefit from ECMO for pediatric ARDS and the trend toward increasing venovenous ECMO (VV-ECMO) use has led to its inclusion in the Pediatric Acute Lung Injury Consensus Conference as a strongly agreed upon recommendation for severe pediatric ARDS. ${ }^{19}$

However, the Pediatric Acute Lung Injury Consensus Conference recommendations supporting use of ECMO for pediatric ARDS highlight the lack of evidence-based selection criteria when determining ECMO candidacy in pediatric patients with ARDS. ${ }^{19}$ In the absence of proven, specific inclusion/exclusion criteria, clinicians must compare outcome data from non-ECMO pediatric respiratory failure and outcome data from available observational ECMO case-control studies. Clinicians must also account for the impact on outcome from other non-respiratory confounding factors, such as comorbidities and pre-ECMO organ dysfunction. Ultimately, decisions to proceed with ECMO and the concomitant risk of potential life-threatening complications must consider: (1) estimated mortality and morbidity from the underlying acute clinical disease process and preexisting comorbidities with and without ECMO; (2) direction of clinical course over serial observations in a time frame that allows assessment of the rate 


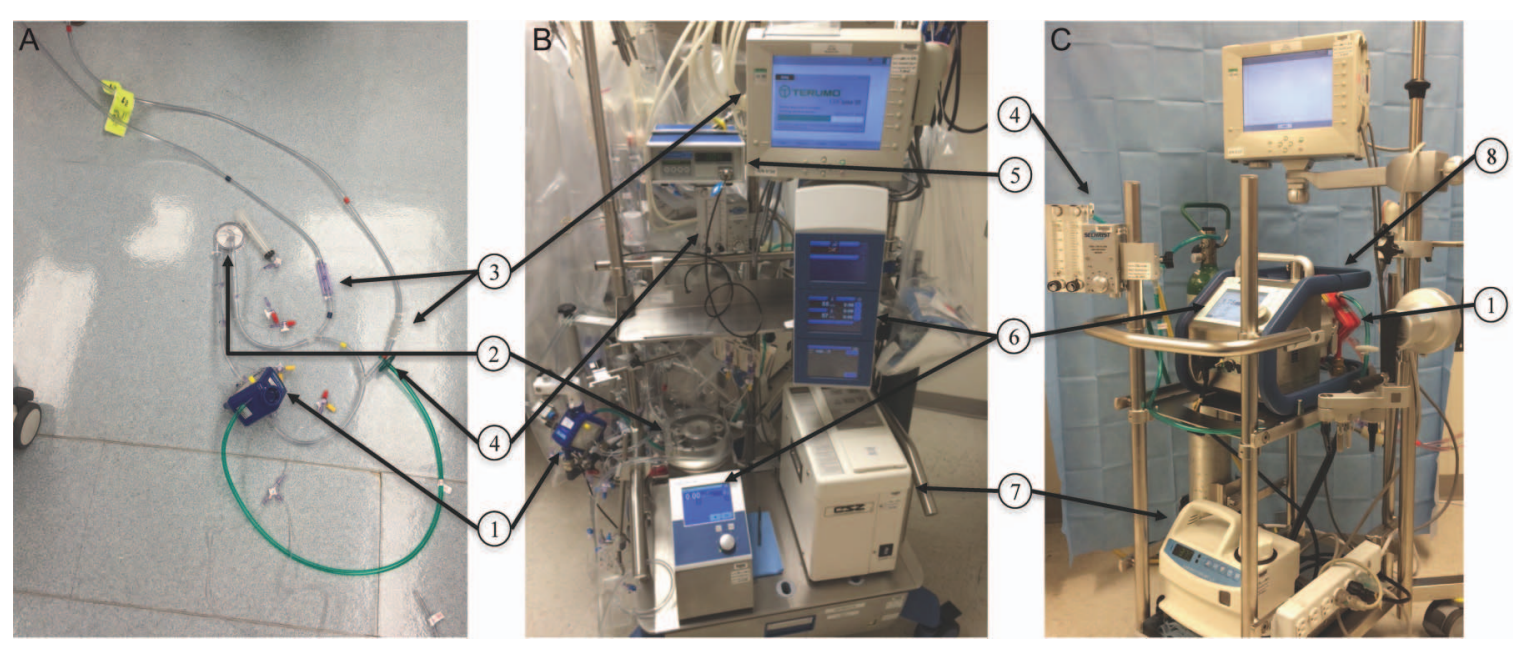

Fig. 1. A: ECMO circuit tubing with component pieces in place, configured with a centrifugal pump. Patient outflow tubing marked with blue tape (venous limb) draws deoxygenated blood from patient into the pump. Patient inflow tubing marked with red (arterial limb) tape returns oxygenate blood to the patient. This circuit is configured with a centrifugal pump interface. B: ECMO cart with all component pieces in place, configured with a rotary pump. C: Maquet Cardiohelp system. 1: Artificial lung (Maquet Quadrox) provides extracorporeal gas exchange. 2: External pump provides driving force for blood flow through the ECMO circuit. This can be either a centrifugal or rotary pump. The blood flow circuit tubing in A is configured for a centrifugal pump interface, whereas B depicts a rotary pump. 3: Blood parameter monitoring system (Temuro CDI) uses fluorescence sensors on the venous and arterial sides to monitor continuously pH, $\mathrm{P}_{\mathrm{CO}_{2}}, \mathrm{P}_{\mathrm{O}_{2}}$, oxygen saturation, hemoglobin/hematocrit, $\mathrm{HCO}_{3}$, and potassium. 4: Gas source delivers fresh medical gas (oxygen and air) modified by a flow meter and blender, shown in B, to the artificial lung via green tubing, shown in A. 5: Blood flow meter continuously monitors blood flow through the ECMO circuit via a sensor on the arterial limb tubing, serving as a direct measure of blood flow. 6: Bioconsole monitors blood flow generated by the external pump and the generated circuit pressures on the venous and arterial limbs. A display screen on the lower console displays flow characteristics generated by the external pump. 7: External heater uses a water bath to rewarm the blood while outside the patient to prevent hypothermia. 8: Maquet Cardiohelp system combines the artificial lung, a centrifugal pump, and bioconsole monitoring system into one unit, allowing smaller circuit priming volumes and a more streamlined overall circuit configuration.

and direction of clinical decompensation; (3) reversibility of the underlying acute clinical disease process and potential candidacy for lung transplantation; and (4) balance between the likelihood of post-survival quality of life and the patient's and family's goals of care.

Reviews on ECMO for adult and neonatal respiratory failure have been published in the past year, and the reader is directed to those references ${ }^{20,21}$ for these 2 patient populations. A similar summary of ECMO for non-neonatal pediatric respiratory failure has been lacking. This review focuses on this patient population and ECMO indications, ventilator management while receiving ECMO, criteria for separation from ECMO, and developing techniques.

\section{ECMO Basics}

ECMO provides cardiopulmonary support by removing a portion of the systemic venous return from a central vein and returning it to the venous circulation (VV-ECMO) or to the arterial circulation (VA-ECMO). In both methods, the drained central venous blood is propelled via a pump through an oxygenator and then heated before returning to the patient. Monitoring and safety devices are in place to provide biochemical and mechanical pro- files to assist in titration of electrolytes, gas exchange, and blood flow parameters (Fig. 1).

VV-ECMO provides only support for gas exchange with blood returning to the central venous circulation with no direct contribution to the systemic arterial circulation (Fig. 2A). Systemic delivery of the oxygenated blood relies on adequate right-ventricular function, a sufficiently low pulmonary vascular resistance and left-atrial pressure, and adequate left-ventricular function. Cannula placement and size must allow simultaneous venous drainage from and return to the patient's central venous circulation at flows sufficient to replace enough of the compromised lung function and maintain adequate oxygenation and ventilation. The efficacy of VV-ECMO can be affected by malpositioned cannulae that limit flow or increase recirculation of blood in the ECMO circuit rather than combining with the patient's circulation. Contraindications to VV-ECMO include right-ventricular failure, pulmonary arterial hypertension requiring significant exogenous pulmonary vasodilators, pulmonary venous obstruction, and left-ventricular failure. In addition, any clinical condition that limits patient systemic venous return (eg, cardiac tamponade, tension pneumothorax) or malpositioned venous cannulae will lead to increased recirculation and subsequent patient de- 
A

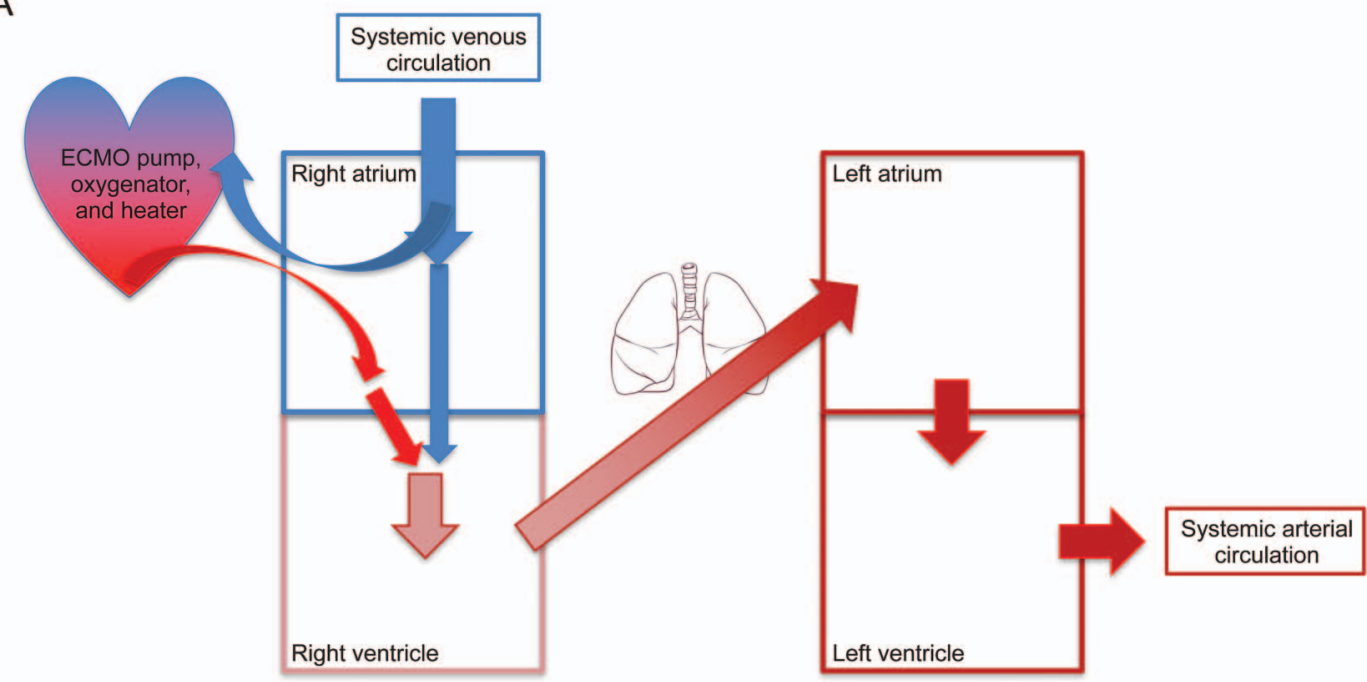

B

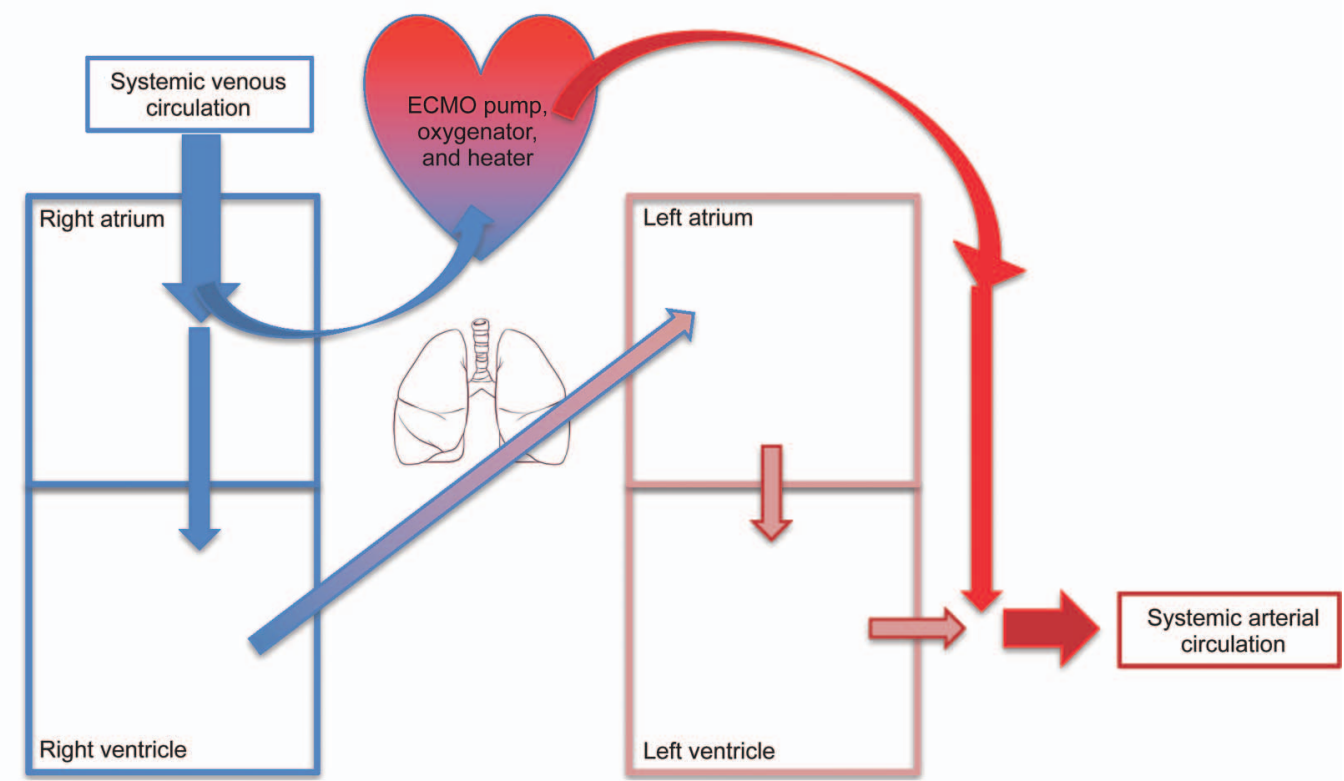

Fig. 2. Diagram of venovenous extracorporeal membrane oxygenation (VV-ECMO) (A) and venoarterial ECMO (VA-ECMO) (B) and patient circulation. Arrows indicate the direction of blood flow through the stylized chambers of the heart, represented by squares. The arrow connecting the right ventricle to the left atrium represents native pulmonary circulation. The heart shape represents the ECMO circuit with pump, oxygenator, and heater. The relative width of the arrows reflects proportional blood flow through the heart chambers and the ECMO circuit. The relative shading of the arrows and outlines of the heart chambers reflects the degree of oxygenation. Systemic venous circulation carries blue blood, contribution of native pulmonary function to oxygenation results in pink blood, the most highly oxygenated blood going from the ECMO circuit to the patient is bright red, and the resultant mixing of highly oxygenated ECMO blood and poorly or partially oxygenated blood leaving the native pulmonary circulation results in dark red blood.

saturation despite preserved ECMO pump or oxygenator function.

In comparison, VA-ECMO both supports gas exchange and supplements cardiac output (Fig. 2B). The portion of systemic venous return that is drained into the ECMO circuit is returned directly to the systemic arterial circulation. Cannula placement and size in VA-ECMO must achieve adequate flows to augment compromised native cardiac output to meet the patient's needs. In the absence of a right-to-left intracardiac shunt, VA-ECMO bypasses the pulmonary circulation with no potential for recirculation of oxygenated blood in the ECMO circuit that can occur in VV-ECMO. As long as ECMO circuit flow is not limited, VA-ECMO can provide higher amounts of oxygenation and ventilation support than VV-ECMO. However, typical flows are unlikely to provide sufficient cardiac support to patients with high cardiac output or vasodilatory shock. 


\section{ECMO for Severe Pediatric Respiratory Failure}

\section{Indications}

\section{Pediatric ARDS}

The literature has previously referred to pediatric ARDS as acute hypoxemic respiratory failure, acute lung injury, and simply ARDS. The 2015 Pediatric Acute Lung Injury Consensus Conference summary ${ }^{22}$ defined pediatric ARDS as a condition characterized by non-cardiogenic, new-onset pulmonary infiltrates in the setting of oxygenation deficit in patients ranging from infants through young adults. The guidelines specifically distinguished pediatric ARDS from the unique conditions seen in perinatal related lung disease and the pathophysiology related to persistent fetal circulation and rapidly changing pulmonary vascular resistance. ${ }^{22}$ No specific upper age limit was set, further emphasizing the similarities between a physically mature teenager and a young adult suffering from ARDS.

The specific criteria outlined for pediatric ARDS were derived from the American-European Consensus Conference adult definitions presented in $1994^{23}$ and the subsequent large body of literature applying these definitions to the pediatric population. The updated Berlin criteria addressed important deficits related to previously missing consideration of applied mean airway pressure but also did not incorporate pediatric considerations. ${ }^{24}$ The most significant addition to the Berlin criteria by the pediatric ARDS definition are the inclusion of noninvasive oxygen saturation measurements to characterize the degree of oxygenation deficit in those pediatric patients lacking arterial blood sampling. Inclusion of $\mathrm{S}_{\mathrm{pO}_{2}} / \mathrm{F}_{\mathrm{IO}_{2}}{ }^{25}$ and oxygen saturation index $\left(\left[\text { mean airway pressure } \times \mathrm{F}_{\mathrm{IO}_{2}} \times 100\right] / \mathrm{S}_{\mathrm{pO}_{2}}\right)^{26,27}$ along with $\mathrm{P}_{\mathrm{aO}_{2}} / \mathrm{F}_{\mathrm{IO}_{2}}$ and oxygenation index (OI $=$ [mean airway pressure $\left.\times \mathrm{F}_{\mathrm{IO}_{2}} \times 100\right] / \mathrm{P}_{\mathrm{aO}_{2}}$ ) was based on studies demonstrating concordance between $\mathrm{P}_{\mathrm{aO}_{2}} / \mathrm{F}_{\mathrm{IO}_{2}}$ and $\mathrm{S}_{\mathrm{pO}_{2}} / \mathrm{F}_{\mathrm{IO}_{2}}$ ratios as well as OI and oxygen saturation index when $\mathrm{S}_{\mathrm{pO}_{2}}$ was $<97 \%$.

Using these oxygenation variables, degrees of pediatric ARDS severity were defined as mild $(4 \leq$ OI $<8$ or $5 \leq$ oxygen saturation index $<7.5)$, moderate $(8 \leq$ OI $<16$ or $7.5 \leq$ oxygen saturation index $<12.3)$, and severe $(\mathrm{OI} \geq 16$ or oxygen saturation index $\geq 12.3$ ) in patients receiving invasive mechanical ventilation. For patients receiving noninvasive ventilation where mean airway pressure measurements are less reliable, oxygenation deficit criteria were defined using a $\mathrm{P}_{\mathrm{aO}_{2}} / \mathrm{F}_{\mathrm{IO}_{2}}$ ratio $\leq 300$ or an $\mathrm{S}_{\mathrm{pO}_{2}} / \mathrm{F}_{\mathrm{IO}_{2}}$ ratio $\leq 264$. This modification implicitly acknowledged the drawbacks of relying on the variations in bedside clinical decisions about the need for invasive arterial access or potential technical challenges in establishing invasive arterial access to define a clinical syndrome.

Defined using these specific pediatric considerations, pediatric ARDS represents as much as $4 \%$ of all pediatric
Table 1. Pediatric ARDS Mortality Risk Factors

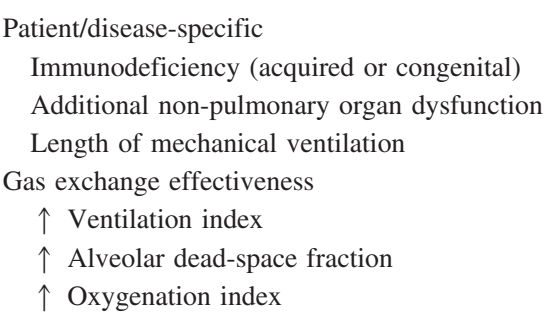

\footnotetext{
The presence of these conditions increases overall mortality risk, and they can be considered as factors that would favor initiation of extracorporeal membrane oxygenation support in the absence of absolute contraindications to extracorporeal membrane oxygenation. With improved technique and anticoagulation management, true absolute contraindications to extracorporeal membrane oxygenation fall into 2 general categories: (1) known irreversible, terminal underlying disease with no viable cure and (2) uncontrollable hemorrhage.
}

ICU admissions ${ }^{28}$ and at a population level occurs at an incidence of 2.0-12.8 cases/100,000 person-years with an overall mortality of $18-35 \% .^{22}$ Several risk factors for mortality have been described and can be categorized as either patient-specific or disease-specific (Table 1). Of the patient-specific risk factors, acquired or congenital immunodeficiency has demonstrated the highest mortality risk, in excess of $70 \%$ and as high as $91 \%$ in patients with acute respiratory failure associated with bone marrow transplantation. ${ }^{30}$ With respect to disease-specific risks, development of additional organ dysfunction syndrome and, in particular, multiple organ dysfunction syndrome have been demonstrated to be the most important mortality predictors. ${ }^{29}$ Erickson et al ${ }^{28}$ demonstrated that the odds ratios of death were highest with renal failure (odds ratio $[95 \% \mathrm{CI}]=11.11[3.95-31.26])$, need for renal replacement therapy (odds ratio $[95 \% \mathrm{CI}]=17.18$ [3.64-31.26]), and multiple-organ failure (odds ratio $[95 \% \mathrm{CI}]=8.34$ [3.42-20.34]).

In addition to the presence of immunodeficiency or organ dysfunction, measures of ventilation and oxygenation also correlate with mortality risk. A ventilation index $\left(\left[\mathrm{P}_{\mathrm{aCO}_{2}} \times\right.\right.$ peak airway pressure $X$ breathing frequency]/1,000) of $>65$ by day 3 of illness had a positive predictive value for mortality of $90 \%$ in a small single-center retrospective study of 39 children. ${ }^{31}$ In another single-center study of 95 subjects with pediatric ARDS, alveolar dead-space fraction $\left(\left[\mathrm{P}_{\mathrm{aCO}_{2}}-\mathrm{P}_{\mathrm{ETCO}_{2}}\right] / \mathrm{P}_{\mathrm{aCO}_{2}}\right)$ also correlated with mortality. Each alveolar dead-space fraction increase by 0.1 increased the mortality odds ratio by $1.92 .{ }^{32}$ Subsequent secondary data analysis demonstrated an alveolar deadspace fraction cut point of 0.23 , with a $46 \%$ versus $13 \%$ mortality for subjects with alveolar dead-space fraction greater or less than this level, respectively. ${ }^{22}$ The OI has demonstrated the best discrimination of mortality risk with an area under the receiver operator curve of 0.747. An OI $>16$, representative of severe pediatric ARDS, appears to be a cut point, with mortality increasing from $<23 \%$ for 
moderate pediatric ARDS to $>30 \%$ for severe pediatric ARDS. Additionally, subjects with an OI $>20$ exhibited a $40 \%$ mortality. ${ }^{22}$ The same subject data set used to derive these OI cut points further demonstrated that each additional OI increase of 1 conferred an increased mortality odds ratio of $1.04 .^{33}$ Using a multivariate analysis, the combination of alveolar dead-space fraction and either OI or oxygen saturation index provided the best mortality prediction with an area under the receiver operator curve $=0.78$, although this was not significantly better than using OI alone. ${ }^{32}$ Combining these 2 measures, an OI $>20$ and an alveolar dead-space fraction $>0.23$ represent reasonable threshold values that identify patients whose mortality risk without ECMO may exceed the reported overall mortality associated with severe pediatric ARDS.

However, the decision to proceed with ECMO support for pediatric ARDS cannot be reduced to identification of preexisting immunodeficiency or developing organ dysfunction or to calculation of oxygenation and ventilation variables. These same variables that carry higher risk of mortality in pediatric ARDS without ECMO also have been associated with worse or unclear outcomes in patients undergoing ECMO support. A review of the ELSO registry through 2004 of patients requiring ECMO for respiratory failure who also had immune-compromised conditions had a somewhat lower overall survival to hospital discharge of $37 \%$ compared with the non-immunocompromised cohort with a survival of $58 \% .{ }^{34}$ Within this group of conditions, none of the 17 patients in the ELSO registry who had undergone bone marrow transplant and required ECMO for respiratory failure before 2004 survived. From 2004 to 2012, the ELSO registry reports 12 bone marrow transplant patients requiring ECMO, 3 of whom survived to hospital discharge (25\%), perhaps reflecting improved overall critical care strategies as well as improved ECMO management. ${ }^{35}$

The impact of organ dysfunction, especially acute kidney injury, before ECMO therapy or that develops while receiving ECMO therapy appears mixed. A single-center analysis of the impact of ECMO therapy on renal function in children demonstrated an improvement in pre-ECMO acute kidney injury soon after the initiation of extracorporeal support. ${ }^{36}$ However, in addition to the renal toxic effects of the underlying disease process and renal hypoxia, acute kidney injury may also be caused by ECMO therapy itself.ECMO-related variables contributing to acute kidney injury include hemolysis and release of free hemoglobin, changes in hemodynamic flow characteristics while receiving ECMO, and impaired hormonal regulation. ${ }^{37,38}$ A review of ELSO registry data from 1998 to 2008 for pediatric respiratory ECMO patients demonstrated an odds ratio for mortality of 1.7 with acute kidney injury that increased further to 2.5 if renal replacement therapy was administered. ${ }^{39}$ In contrast, a single-center retrospective study demonstrated no difference in ECMO survival with or without the need for renal replacement therapy during the ECMO course. ${ }^{40}$ However, the majority $(67.4 \%)$ of these ECMO subjects had renal replacement therapy initiated due to fluid overload rather than renal failure (20.9\%) and may misrepresent the relationship between acute kidney injury and ECMO survivability. Furthermore, the study recruited too few subjects to detect a mortality difference, requiring approximately 10 -fold more subjects in order to be adequately powered. ${ }^{41}$ Whether acute kidney injury resulting from hypoxemic and inflammatory stress seen in pediatric ARDS can be prevented or ameliorated with improved oxygenation and ventilation provided by ECMO or whether ECMO contributes to development or worsening of acute kidney injury remains unclear.

The length of mechanical ventilation before the initiation of ECMO appears to also correlate with survival. Historically, the first ECMO trial in 1978 listed "duration of the precipitating pulmonary insult last[ing]...more than 21 days" as an exclusion criterion. ${ }^{2}$ Subsequently, in 1993, Moler et al $\mathrm{a}^{42,43}$ determined a cut point of approximately $7 \mathrm{~d}$ of mechanical ventilation before ECMO initiation as an independently associated variable with mortality. More recently, a 2012 review of the ELSO registry demonstrated that decreased survival odds occurred when pre-ECMO length of mechanical ventilation exceeded $14 \mathrm{~d} .{ }^{44}$

Similarly, previously considered absolute contraindications for ECMO, such as recent trauma, ${ }^{45}$ septic shock, ${ }^{46}$ bone marrow transplant, ${ }^{35}$ and diffuse alveolar hemorrhage, ${ }^{47,48}$ each have been successfully treated with ECMO. As experience builds and techniques improve, the only absolute contraindications to ECMO are quickly becoming (1) known irreversible, terminal underlying disease with no viable cure and (2) uncontrollable hemorrhage despite maximal medical and surgical therapy. Ultimately, evaluating mortality risk of pediatric ARDS with or without ECMO is inexact at best and must consider not just the variables discussed above, but also the intensity and rate of clinical deterioration or lack of clinical improvement.

ECMO complications fall into 4 general categories related to (1) mechanical complications related to equipment failure and hemolysis from physical damage to the red cell; (2) bleeding and thrombolytic complications impacting the circuit, patient, or both; (3) infection; and (4) organ dysfunction (Table 2). The risk of these complications increases with longer ECMO duration although no data exist quantifying the degree of cumulative risk over time.

These ECMO-specific complications and other consequences of both ECMO therapy and the underlying disease process for post-survival morbidity must also be considered in the decision-making process. The earliest reports of long-term neurodevelopmental outcomes following ECMO support focused on survivors of ECMO applied in the neonatal population and compared the incidence of 
Table 2. Pediatric Respiratory Extracorporeal Membrane Oxygenation Complications Voluntarily Reported to the Extracorporeal Life Support Organization Representing 7,710 Cases in Participating Extracorporeal Membrane Oxygenation Centers From 1990 to July 2016

\begin{tabular}{|c|c|}
\hline Complication & Incidence $(\%)$ \\
\hline \multicolumn{2}{|l|}{ Mechanical: equipment } \\
\hline Air in circuit & 4.2 \\
\hline Cannula problems & 15.3 \\
\hline Circuit rupture & 2.3 \\
\hline Heat exchanger malfunction & 0.4 \\
\hline Oxygenator failure & 10.6 \\
\hline Pump malfunction & 2.2 \\
\hline $\begin{array}{l}\text { Mechanical: hemolysis (plasma-free hemoglobin } \\
\qquad>50 \mathrm{mg} / \mathrm{dL} \text { ) }\end{array}$ & 10.2 \\
\hline \multicolumn{2}{|l|}{ Bleeding } \\
\hline Cannula site & 18.3 \\
\hline Central nervous system hemorrhage & 6.4 \\
\hline Disseminated intravascular coagulation & 5.4 \\
\hline Gastroinstestinal & 4.1 \\
\hline Pulmonary hemorrhage & 8.1 \\
\hline Surgical site & 12.6 \\
\hline \multicolumn{2}{|l|}{ Clotting } \\
\hline Bridge & 3.5 \\
\hline Central nervous system infarction & 4.2 \\
\hline Hemofilter & 4.5 \\
\hline Oxygenator & 11.1 \\
\hline Other & 12.3 \\
\hline Infection (culture-proven) & 16.8 \\
\hline \multicolumn{2}{|l|}{ Organ dysfunction } \\
\hline $\begin{array}{l}\text { Hyperbilirubinemia }(\text { direct }>2 \mathrm{mg} / \mathrm{dL} \text { or } \\
\quad \text { total }>15 \mathrm{mg} / \mathrm{dL})\end{array}$ & 5.2 \\
\hline \multicolumn{2}{|l|}{ Renal failure } \\
\hline Creatinine $1.5-3.0 \mathrm{mg} / \mathrm{dL}$ & 8.8 \\
\hline Creatinine $>3.0 \mathrm{mg} / \mathrm{dL}$ & 4.1 \\
\hline Dialysis required & 11.1 \\
\hline Hemofiltration required & 23.2 \\
\hline Seizures & 5.4 \\
\hline
\end{tabular}

intellectual disability, learning disability, and cerebral palsy with healthy normal controls who had not required neonatal intensive care unit or special care nursery admission following delivery. A single-center cohort of neonatal ECMO survivors undergoing comprehensive neurocognitive assessment and parental and school survey assessments demonstrated major disability (mental or motor disability, sensorineural impairment, or seizure disorder) in 17 of 103 (17\%) study subjects. ${ }^{49}$ Major disability correlated highly with hemorrhagic or non-hemorrhagic intracranial lesions, although the relationship between these intracranial lesions and the ECMO course was not described. Parents of these ECMO-treated subjects also reported significantly more behavioral adjustment problems in $42 \%$ versus $16 \%$ of controls. Half of the ECMO subjects were classified as being at risk for school failure, over twice the rate of controls. This report, however, compared ECMO-treated subjects with healthy controls rather than critically ill neonates who did or did not receive ECMO. This weakness was addressed by the 7-y follow up of a randomized control trial of ECMO for neonatal respiratory failure. ${ }^{9}$ This analysis determined that cognitive ability, neuromotor performance, and health services utilization were similar in the ECMO and conventional treatment groups, suggesting that longterm neurocognitive and health issues were related more to the underlying disease process than to ECMO itself.

Few pediatric studies assessing the long-term impact on post-survival morbidity have been completed. Those that have been done have had limited subject numbers or have had indirect, less robust assessment methods. These pediatric reports also only provide overall incidence rates of disability without comparison with critically ill children not treated with ECMO. These studies have reported (1) a $16 \%$ prevalence of seizures and/or developmental delay and a $62 \%$ hospital readmission rate within a median of 1.2 y using a statewide administrative database and ICD-9 codes $^{50}$; (2) $38 \%$ mild or moderate disability based on the pediatric overall performance category scale at a median of $>5 \mathrm{y}$ after ECMO based on parental telephone interview ${ }^{51,52}$; and (3) 70\% incidence of abnormal quality of life based on retrospective review of post-ECMO, predischarge medical records and prospective parental telephone survey. ${ }^{53}$ Beyond a single report of a single pediatric patient rescued with ECMO for necrotizing pneumonia from pneumonia, ${ }^{54}$ there are no published data describing the subsequent pulmonary morbidity and decrease in lung function, measured either formally via pulmonary function testing or informally with subjective assessment of exercise tolerance.

Consequently, the decision to proceed with ECMO in the setting of pediatric ARDS in a previously healthy child with no additional non-pulmonary organ dysfunction can be made by following serial measurements of a combination of OI or oxygen saturation index and alveolar deadspace fraction to determine clinical trajectory. However, in the face of concomitant immune deficiency or organ dysfunction, this decision is much more challenging with limited definitive evidence to guide the clinician and family. The question of long-term survival and disability also has limited data upon which to base life-and-death decisions. In this setting, realistic expectations among the medical team and between the medical team and family should be set as early as possible with milestones set to help guide decisions surrounding futility of ongoing extracorporeal support to meet overall goals of care and quality-of-life expectations. 


\section{Bridge to Lung Transplantation}

First performed in 1977,55 ECMO as a bridge to lung transplantation (LTx) was met with extreme hesitation and ultimately considered by most transplant centers as a contraindication. ${ }^{56}$ However, with improved techniques both in LTx and in ECMO support, case reports and series have demonstrated acceptable outcomes relative to overall LTx survival. The first series describing long-term survival was published in 1993 and described 5 subjects, age 19-46 y, supported with ECMO ranging from 8 to $292 \mathrm{~h}$ before LTx, 3 of whom survived $>1$ y after LTx. ${ }^{57}$ As LTx experience increased, the field recognized the significant imbalance between organ availability and need with many patients dying while waiting for LTx and an average wait time of nearly 2 y by 1998 . In this setting, the need for invasive mechanical ventilator support, let alone ECMO, was felt to be a relative contraindication for LTx as a way to limit organ wastage. ${ }^{58}$

Advances in both transplant and extracorporeal support techniques and understanding continued to push the envelope of therapy. In 2010, a subsequent series and review of both mechanical ventilation and ECMO before LTx described 51 patients included in the United Network for Organ Sharing database from 1987 to $2008 .{ }^{59}$ This summary of the United States experience reported survival at 24 months as 45, 57, and 70\% for patients requiring ECMO, invasive mechanical ventilation, or neither before LTx, respectively. Clearly, patients requiring mechanical respiratory support in the form of either mechanical ventilation or ECMO experienced markedly worse survival than patients undergoing LTx with sufficient cardiopulmonary function to breathe spontaneously. In this report, the authors pose the ethical question of whether ECMO as a bridge to LTx was appropriate and how to balance between individual patient benefit and population benefit in the setting of resource scarcity. Nevertheless, in the 2 decades of the 1990s and the 2000s, the number of patients receiving ECMO support simultaneously listed for LTx increased nearly 5 -fold from 22 to $104 .{ }^{60}$

As technical sophistication increased in critical care and ECMO management and patients were able to be maintained in an awake state to allow participation in physical conditioning while receiving extracorporeal support, results following ECMO as a bridge to LTx began to close the survival gap. Since 2005, 2 factors have been shown to correlate with improved outcomes with ECMO support before LTx: a mode of respiratory support that allows the ability to ambulate while receiving ECMO and the duration of ECMO before LTx. A report of 11 subjects with a mean age of $34 \mathrm{y}$ that compared the method of respiratory support while receiving ECMO described a 1-y survival of 6 of $7(85 \%)$ in a spontaneously breathing noninvasive support group compared with only 2 of $4(50 \%)$ in a group receiving invasive mechanical ventilation. ${ }^{61}$ A review of the United Network for Organ Sharing national database from 2005 to 2013 of adult patients $\geq 18$ y old evaluated outcomes based on level of respiratory support at the time of LTx and defined 4 groups: invasive mechanical ventilation only, ECMO only, ECMO with invasive mechanical ventilation, and neither ECMO nor invasive mechanical ventilation. This retrospective database review identified $>12,000$ adult LTx recipients, with 796 receiving some combination of ECMO or invasive mechanical ventilation. Patients requiring neither mode of support had the best 1and 3-y survival at 89.4 and $67.0 \%$, respectively. Patients requiring ECMO alone had lower 1-y survival at 70.4\% but equivalent 3-y survival (64.5\%) to the no-support group. Need for invasive mechanical ventilation had the worst 3 -y outcomes, with only $57.0 \%$ survival for invasive mechanical ventilation alone and $45.1 \%$ survival for invasive mechanical ventilation and ECMO need at the time of LTx. ${ }^{62}$

Duration of time receiving ECMO while waiting LTx also appears to impact outcomes, although the data are less robust. In a single report of 17 subjects receiving ECMO bridge who were able to undergo LTx, investigators observed a difference in outcome based on ECMO duration $\leq 14 \mathrm{~d}$ (early) or $>14 \mathrm{~d}$ (late). The 9 early LTx from ECMO bridge subjects were all alive at $1 \mathrm{y}$ post-LTx compared with only 4 of 8 subjects surviving to $1 \mathrm{y}$ in the late LTx from ECMO bridge group. Notably, the length of invasive mechanical ventilation may have been a significant confounder. The late LTx from ECMO bridge patients received nearly 4 -fold longer ( $45 \mathrm{~d}$ vs $12 \mathrm{~d}, P=.03$ ) invasive mechanical ventilation following LTx than the early group. ${ }^{63}$

In a subsequent 2015 systematic review, the authors reviewed 14 retrospective clinical case series with a combined total of 441 subjects ranging in age from older teenagers to the 60 s and reported 1-y survival between 50 and 90\%.64 Although these authors found no definitive evidence detailing a best strategy, they concluded that current evidence clearly supported the use of ECMO as a way to sustain select patients with end-stage respiratory failure awaiting LTx. Further, avoidance of invasive mechanical ventilation if at all possible and aggressive pursuit of ambulatory ECMO to preserve physical conditioning appeared to be key in achieving acceptable long-term outcomes and avoiding organ wastage. In all of these reports, subject selection criteria have been crucial. Criteria for eligibility for ECMO support as a bridge to LTx have been proposed and include absence of additional non-pulmonary organ failure, absence of severe neurologic impairment, relatively well-preserved physical conditioning, absence of systemic infection or multidrug-resistant pulmonary infection or colonization, and unmanageable bleeding diathesis. ${ }^{65}$ These exclusion criteria are not absolute and ultimately strive to 
achieve identification of those patients most likely to survive both an ECMO course and the eventual LTx.

These large case series have described older teenagers and adults. In contrast, the pediatric-specific experience is far more limited. A review of the United Network for Organ Sharing database from 2000 to 2013 included 17 pediatric subjects who were receiving ECMO at the time of LTx. Subsequent comparison with subjects not requiring ECMO at the time of LTx was limited by lack of ability to find an appropriately matched control in 4 and lack of data in another 1 , leaving 12 cases available for comparison with matched non-ECMO controls. In this comparison, the authors found no increase in risk of death in the ECMO group with the longest available information on survival up to $4 \mathrm{y}$ after LTx. ${ }^{66}$ Other data on the pediatric experience with ECMO bridge to LTx are limited to case series. In the same paper reporting the United Network for Organ Sharing pediatric experience, the authors describe their own single-center experience of successful ECMO bridge to LTx in 2 of 3 subjects; the third subject died while awaiting transplant. ${ }^{66}$ Another group reported 5 pediatric subjects (age range 10-20 y) with pre-LTx ECMO support undergoing LTx while still receiving ECMO but do not report survival to hospital discharge in this specific sub-cohort. ${ }^{67} \mathrm{~A}$ separate group report 4 pediatric subjects, age 11-15y, undergoing ECMO bridge to LTx, all of whom survived to hospital discharge. ${ }^{65}$ The largest individual series described 15 pediatric subjects $0.2-18$ y old who underwent ECMO before LTx, only nine of whom were receiving ECMO at the time of LTx. Of the entire group, 6 subjects survived to hospital discharge. There was a trend toward statistical significance for survival in subjects able to wean off of ECMO before LTx (4 of 6) compared with subjects still receiving ECMO (2 of 9) at the time of LTx $(P=.09){ }^{68}$ Limited to no information was provided in these pediatric-specific case reports on level of activity during ECMO support.

An even smaller number of case reports have described pediatric ambulatory ECMO, demonstrating proof of principle. Thus far, 5 separate case reports have described a total of 9 older children ranging in age from 8 to $19 \mathrm{y}$ who underwent VV-ECMO as a successful bridge to LTx, all but one of whom survived to hospital discharge. ${ }^{69-73}$ Most recently, a sixth report described successful use of ambulatory VA-ECMO in a 4-y-old girl who underwent heartlung transplant for primary pulmonary hypertension and refractory right-ventricular failure and was ultimately discharged home. ${ }^{74}$

Ultimately, ECMO as a bridge to LTx represents a viable and increasingly utilized treatment for what is a terminal condition without LTx. The role of ECMO to either salvage refractory respiratory failure or to prevent complications of invasive mechanical ventilation with subsequent loss of physical conditioning and worsening of ven- tilator-induced lung injury is only now beginning to be described. Patient selection and thorough and repeated discussions among the multi-professional medical team and family play an essential role during this process. Multiple areas requiring investigation remain, including: (1) timing of ECMO initiation; (2) impact of duration of time receiving ECMO before LTx; (3) relative versus absolute contraindications to use of ECMO as a bridge to LTx; (4) the relative impact of invasive mechanical ventilation versus the ability to maintain an awake and active state even if invasive mechanical ventilation is required; (5) feasibility of this approach in a population where wait times for suitably sized organs are significantly longer than in older teenagers or adults; (6) how best to identify those patients with the highest likelihood of benefit and meaningful survival; (7) the best methods to maintain physical conditioning and rehabilitation in developmentally appropriate but immature children; (8) the health-care costs associated with this approach and resource utilization requirements; (9) ethical considerations regarding the balance between individual versus population benefit; and (10) the informed consent process and how to best achieve a shared understanding of therapeutic limitations balanced with patientdefined goals of care.

\section{Other}

ECMO applied to pediatric ARDS and as a bridge to LTx has been most frequently reported in the literature. Use of ECMO for pediatric asthma has limited retrospective data that suggest excellent survival with relatively shorter time spent receiving ECMO but offers little insight into whether ECMO offers morbidity or mortality benefit. A review of the ELSO registry from 1993 to 2007 identified 71 cases of ECMO in pediatric near-fatal asthma with $83 \%$ survival to discharge. ${ }^{75}$ In comparison, a review of 261 pediatric ICU subjects with asthma requiring intubation, 3 of whom received ECMO support, demonstrated $84 \%$ survival. ${ }^{76} \mathrm{~A}$ case series of 13 children receiving ECMO for asthma from a single center reported $100 \%$ survival with no neurologic sequelae. ${ }^{77}$ However, the question of whether ECMO improves morbidity or mortality when compared prospectively with aggressive medical management remains unanswered.

Single case reports or small case series in children have been published for a multitude of conditions supported with ECMO while the underlying disease was treated either medically or surgically. These include poisonings, life-threatening upper-airway obstruction, trauma, refractory air leak from a multitude of underlying infectious or traumatic causes, and even diffuse alveolar hemorrhage. ${ }^{47,78-80}$ As experience builds and ECMO technology and practice continues to advance, the rate of high morbidity or high mortality complications from ECMO sup- 
port will probably decrease, and more case reports will appear of ECMO use for other indications requiring a brief or prolonged period of cardiopulmonary support pending resolution of the underlying disease process.

\section{ECMO Transport}

The United States Air Force published one of the first experiences with inter-facility ECMO transport. ${ }^{81}$ These pioneers described the development of an inflight ECMO system that would account for a multitude of factors, including extreme temperature variation, vibration, acceleration and deceleration forces, electromagnetic interference between aircraft electronic systems and the ECMO equipment, equipment failure, and power failure. After extensive testing, the Air Force successfully deployed an ECMO transport system to support neonates born to United States military members by bringing them from various neonatal ICUs throughout the world back to Wilford Hall Medical Center in San Antonio, Texas, home of the Air Force's only ECMO program.

Since then, long-range, inter-facility ECMO transport has spread successfully across North America and Europe. Whereas the Air Force has historically provided the longest distance $(>12,000 \mathrm{~km}$ from Okinawa, Japan to San Antonio, Texas ${ }^{82}$ ), the deployment of long-range ECMO transport teams has allowed a significant increase in the geographic range of hospitals whose patients have access to ECMO support. Reported pediatric outcomes from single-center experiences to national and international programs have mirrored overall ECMO outcomes for nonECMO transport subjects with $\sim 50-70 \%$ survival to discharge. ${ }^{82-86}$ Impressively, despite the complexity of combining ECMO support with ground and air travel, no deaths have been reported during transport in any of these large case series.

In each of these descriptions, patient selection, stringent adherence to safety protocols, and significant investment in personnel education and training represent the sine qua non of inter-facility ECMO transport. Although the specific makeup of the ECMO transport team appears to have some geographical variation, with European centers incorporating more anesthesiologists relative to North American centers, ${ }^{87}$ the consistent elements in all ECMO transport centers lie in exhaustive preparation and both individual and team education and training.

\section{Ventilator Management During ECMO}

Little evidence exists regarding the ideal mode of ventilation while receiving ECMO. Existing reports are all retrospective in nature, primarily reporting observations of current practice state or offering expert opinion. From 1986 to 2006, a review of the ELSO database found little dif- ference in airway pressures and ventilator rate between survivors and non-survivors. Median peak airway pressure, PEEP settings, and ventilator rate remained remarkably consistent at $28-30,10$, and 10 , respectively. The authors emphasized the need for lung rest to avoid any further exacerbation of ventilator-induced lung injury and subsequent worsened inflammation. ${ }^{88}$ This practice convention has been codified into expert opinion from ELSO guidelines and incorporated into clinical trial protocols, including the adult ECMO CESAR trial. ${ }^{89}$

In contrast, a database review of ECMO centers in France and Australia from 2007 to 2013 found a correlation between improved survival and higher PEEP (12-14 vs 10$12 \mathrm{~cm} \mathrm{H}_{2} \mathrm{O}$ ) with slightly higher tidal volumes (4-6 vs $2-4 \mathrm{~mL} / \mathrm{kg}$ ) following ECMO initiation..$^{90}$ These small but potentially meaningful differences in PEEP and tidal volume reflect a contrasting approach to lung rest. Rather than targeting lung rest, a higher PEEP and tidal volume approach emphasizes maintenance of lung recruitment during ECMO support. This approach emphasizes the avoidance of progressive alveolar collapse, thereby potentially improving lung recovery through minimizing pulmonary vascular leak and inflammation caused by atelectasis. These 2 opposite approaches to mechanical ventilation are also reflected in a survey of international ECMO centers and stated overall goals after ECMO initiation. Of the 141 respondents to this survey, $109(77 \%)$ indicated lung rest as the primary mechanical ventilation goal during ECMO, compared with $12(9 \%)$ indicating lung recruitment as the primary goal. Interestingly, another $12(9 \%)$ responded that the primary goal was a combination of both rest and recruitment, although specific description of how this was achieved was not solicited. ${ }^{91}$

The use of lung-protective or ultra-lung-protective ventilator strategies may result in delivery of tidal volumes that are less than anatomic and physiologic dead space until pulmonary compliance improves. Practitioners are then faced with the challenge of causing further atelectasis and increase in pulmonary vascular resistance with negative consequences for right-ventricular afterload. Concurrent application of airway clearance techniques and intermittent recruitment maneuvers may reduce atelectasis from lung-protective ventilator strategies and subsequently facilitate earlier successful separation from ECMO support. Pediatric case series have also described successful use of routine therapeutic bronchoscopy with ${ }^{92}$ or without simultaneous use of high-frequency percussive ventilation, a ventilator mode that some have advocated as a superior ventilator mode in the setting of obstructive secretions in pediatric ARDS. ${ }^{93}$

Taken a step further, some centers have reported successful extubation during ECMO support. ${ }^{94-97}$ In the largest single-center series, Anton-Martin et al described 16 subjects ranging in age from $2 \mathrm{~d}$ to $17 \mathrm{y}$ old who were 
successfully extubated at some point during their ECMO treatment provided between the years 2010 and $2013 .{ }^{97} \mathrm{In}$ 12 of these cases, refractory respiratory failure necessitated ECMO support, 2 additional cases had mediastinal masses, and the remaining 2 had cardiac failure requiring ECMO. Eleven subjects survived their ECMO course. The authors reported that the 5 deaths were not related to extubation while receiving ECMO. Time from ECMO cannulation to extubation ranged from 0 to $19 \mathrm{~d}$; total ECMO duration ranged from 4 to $84 \mathrm{~d}$; and the ratio of days extubated receiving ECMO to total days receiving ECMO ranged from 0.14 to 1 . Respiratory support while extubated receiving ECMO varied from room air to noninvasive bi-level positive airway pressure. Importantly, all subjects underwent serial therapeutic bronchoscopies as necessary to fully clear any secretions from large proximal airways before extubation.

Extubation during ECMO presents a tantalizing goal, potentially allowing for significantly less sedation in the absence of noxious pharyngeal stimulation from the endotracheal tube, spontaneous breathing and coughing to facilitate airway clearance, and increased ability to perform progressive rehabilitation and activity. However, some authors have proposed that regional lung injury can occur regardless of how high transpulmonary pressures $\left(\mathrm{P}_{\text {lung }}=\mathrm{P}_{\text {alveolus }}-\mathrm{P}_{\text {esophagus }}\right.$, where the pleural pressure is estimated by the esophageal pressure) are generated. ${ }^{98,99}$ Patients experiencing increased spontaneous respiratory drive who generate high patient effort and significantly negative pleural pressures can experience equally high $\mathrm{P}_{\text {lung }}$ as the fully paralyzed patient receiving positive-pressure ventilation with high pressure gradients. Lung stress and subsequent ventilator-induced or patient self-induced lung injury then occurs based on regionally experienced pressure gradients. Thus, in the extubated patient receiving ECMO support who is demonstrating high diaphragmatic work and generating highly negative pleural pressures with high transpulmonary gradients, lung injury may still be occurring, particularly in those areas of the lung most affected by the underlying disease process. In this situation, lung protection would be compromised and recovery potentially delayed. Moreover, the inflammatory process and cascade generated by additional lung injury would not be avoided, thereby delaying lung recovery in those patients. For those patients receiving ECMO as a bridge to LTx, however, being able to extubate during ECMO offers significant advantages to optimize non-pulmonary function and outcomes after transplant.

Ultimately, prospective investigation comparing different ventilator approaches is needed. Certainly, the literature regarding ECMO as a bridge to LTx as discussed above suggests that earlier separation from invasive mechanical ventilation correlates with improved outcomes following LTx. However, in this setting, there is little need to attempt to preserve lung function or maintain lung recruitment, since the end goal is replacement of the unrecoverable lungs. In contrast, use of a low-tidal volume $(4-6 \mathrm{~mL} / \mathrm{kg})$ and high-PEEP strategy has become part of the accepted management for ARDS to minimize ventilator-induced lung injury and maximize eventual lung healing and recovery. The use of ECMO to supplement gas exchange to allow tolerance of these low-tidal volume and high-PEEP goals may ultimately reduce the degree of postsurvival debilitation.

\section{Criteria for Separation From ECMO}

Even less evidence exists for specific thresholds of lung recovery that allow safe discontinuation from ECMO support. In the absence of unmanageable ECMO complications, current practice principles target demonstration of adequate ventilation and oxygenation without ECMO support before separation and decannulation. In the setting of VV-ECMO, weaning from extracorporeal support is accomplished by decreasing and ultimately discontinuing gas flow (sweep gas) to the oxygenator. Once the sweep gas flow is zero, any oxygenation or ventilation results from the patient's lung function. If the patient is unable to achieve adequate gas exchange, ECMO support can be reinitiated simply by restoring gas flow to the oxygenator. In VAECMO, weaning bypass support is achieved by decreasing pump flow and ultimately separating ECMO flow from the patient's circulation while leaving the cannula in place. This can be accomplished by recirculating ECMO flow through a bridge linking the arterial and venous limbs of the circuit with intermittent flashes of flow through the cannula to maintain cannula patency, by disconnecting the circuit and connecting the cannula with tubing and a pump that allows minimal blood flow through an external arteriovenous shunt, or by disconnecting the circuit and instilling a heparin lock into the cannula to prevent clot formation. ${ }^{100}$ The time frame over which these weaning maneuvers are accomplished differs in rate and varies from center to center and from individual to individual. The length of time observing tolerance without ECMO support also varies from a few to several hours, depending on the patient's status and initial indications for ECMO.

Specific patient criteria demonstrating stability without ECMO support include markers of adequate oxygenation and ventilation and adequate cardiac output to meet demands. These cardiopulmonary function parameters must then be maintainable with levels of respiratory or cardiac support that provide sufficient room for increased titration in the event of mild to moderate patient decompensation following decannulation. Specific cardiopulmonary function parameters and specific levels of non-ECMO support that correlate with successful discontinuation of ECMO support have not been evaluated. One reasonable approach 
would be to target OI or oxygen saturation index and alveolar dead-space fraction meaningfully less than the thresholds that triggered initiation of ECMO. Normal lactate and mixed venous oxygen saturation represent cardiac output measures that can also guide decisions regarding ECMO discontinuation.

Ultimately, the underlying disease process prompting ECMO support at the outset must have improved sufficiently that the patient's clinical condition remains stable without ECMO. In those situations where clinical improvement is not achievable and the patient is not an LTx candidate or a catastrophic ECMO complication occurs, making recovery impossible, ECMO should be terminated, and the patient's care goals should be redirected to supportive comfort measures. This decision is clearly difficult and cannot be made unilaterally. Because such a situation is a potential result for every case involving ECMO, attention must be placed on establishing, nurturing, and preserving collaborative relationships among the family, medical, surgical, and ECMO teams from the beginning of ECMO support and through the rest of the ICU and hospital stay. For an introduction to the ethical dilemmas that can ensue in this situation, the last chapter of the ECMO Red Book, 4th edition, provides a concise summary. ${ }^{101}$

\section{Developing Techniques}

\section{High-Frequency Percussive Ventilation}

High-frequency percussive ventilation was first described in the literature in 1988 as a means of achieving the goal of hyperventilation with lower peak airway pressures compared with conventional ventilation $\left(34 \mathrm{~cm} \mathrm{H}_{2} \mathrm{O}\right.$ vs $62 \mathrm{~cm} \mathrm{H}_{2} \mathrm{O}$ ) in 38 adult trauma subjects with multipleorgan system injury and traumatic brain injury resulting in refractory increased intracranial hypertension. ${ }^{102}$ Additional investigators reported positive results with high-frequency percussive ventilation to decrease the incidence of barotrauma and subsequent pneumothorax or subcutaneous emphysema in adult subjects with inhalational lung injury. ${ }^{103}$

In the pediatric population, a subsequent report in 26 children with severe burn injuries and severe inhalational injury found that compared with conventional ventilation, high-frequency percussive ventilation resulted in improved respiratory compliance, lower peak inspiratory pressures, and fewer episodes of pneumonia. ${ }^{104}$ Most recently, in a retrospective observational study from Children's Hospital of Philadelphia, 31 pediatric subjects with pediatric ARDS who had failed conventional ventilation demonstrated that within $24 \mathrm{~h}$ of high-frequency percussive ventilation initiation, all measures of oxygenation efficiency (OI, oxygen saturation index, $\mathrm{P}_{\mathrm{aO}} / \mathrm{F}_{\mathrm{IO}_{2}}$, and $\mathrm{S}_{\mathrm{pO}_{2}} / \mathrm{F}_{\mathrm{IO}_{2}}$ ) improved significantly with no change in mean airway pressure; ventilation measured by $\mathrm{P}_{\mathrm{aCO}_{2}}$ also improved significantly even as peak airway pressures decreased. ${ }^{93}$ With the successes seen in their experience with high-frequency percussive ventilation in ARDS, the group in Philadelphia initiated high-frequency percussive ventilation as the standard mode of ventilation for all pediatric patients requiring ECMO support for pediatric ARDS. Compared with historical controls, subjects receiving highfrequency percussive ventilation while receiving ECMO experienced more ECMO-free days at $30 \mathrm{~d}$ post-ECMO initiation, indicating both improved survival at $30 \mathrm{~d}$ and shorter time spent receiving ECMO in the high-frequency percussive ventilation group. However, subjects receiving high-frequency percussive ventilation during ECMO also received more frequent therapeutic bedside flexible bronchoscopy to assist with secretion clearance. ${ }^{92}$ Whether high-frequency percussive ventilation offers benefit in all patients with pediatric ARDS requiring ECMO support remains to be seen. Certainly, application of high-frequency percussive ventilation, perhaps best applied in conjunction with serial therapeutic bronchoscopies, would fall under a lung recruitment ventilator strategy and appears to be an effective means of clearing inspissated airway secretions.

\section{Pumpless Extracorporeal Gas Exchange}

A primary disadvantage of ECMO resides in the pump that drives blood flow through the extracorporeal circuit. Presence of the pump necessarily increases tubing length and exposes red blood cells to physical damage, leading to hemolysis and release of plasma-free hemoglobin, platelet destruction, and an increased inflammatory response. The increased non-organic surface area exposed to blood also serves as an inflammatory trigger. In older patients, a pumpless extracorporeal circuit with an artificial lung (interventional lung assist) provides a low pressure oxygenator that provides supplemental oxygenation and ventilation but depends on the patient's native systemic cardiac function to drive blood flow through the arterial cannula, across the oxygenator membrane, and back to the systemic venous circulation. This external arteriovenous shunt requires relatively intact left-ventricular function and preserved mean arterial pressure in order to maintain sufficient blood flow through the oxygenator. Exact blood flow through the external circuit cannot be controlled externally, and changes in cardiac function or vascular tone greatly compromise the amount of extracorporeal support. ${ }^{105}$ In younger pediatric patients, the left ventricle's ability to accommodate the increased output requirements makes this approach less viable.

In contrast, the paracorporeal lung assist device provides an external venoarterial shunt that directs deoxygen- 
ated blood from the pulmonary artery through the oxygenator and back into the systemic arterial circulation via the left atrium. Elevated pulmonary artery pressures, as seen in severe pulmonary hypertension, provide the driving pressure gradient that generates blood flow through the external circuit and low-resistance oxygenator. The driving forces here are dependent on increased pulmonary artery pressures. The external circuit offloads the right ventricle in much the same way as an atrial septostomy does with the significant added benefit that the shunted blood becomes oxygenated by the paracorporeal lung assist device. Because of the need for elevated pulmonary artery pressures, this technique has been applied thus far exclusively in patients with primary pulmonary hypertension or pulmonary hypertension related to alveolar capillary dysplasia who were awaiting lung transplantation. ${ }^{106-108}$ Each of these patients had initially required rescue with VA-ECMO and was subsequently transitioned to the paracorporeal lung assist device to facilitate improved physical conditioning and separation from invasive mechanical ventilation. The subsequent report detailing the technical aspects and subject experience to date of this approach highlights the ability to minimize sedation, allow extubation, and maximize rehabilitation. ${ }^{109}$ Whether this technique can be applied in secondary pulmonary hypertension due to primary parenchymal lung disease is yet to be determined.

\section{Summary}

In the acute setting when ECMO is being considered, time is often limited to make assessments of the 4 elements listed in the Introduction: (1) estimated mortality and morbidity with versus without ECMO; (2) direction and rate of change of clinical condition; (3) disease reversibility and potential candidacy for LTx; and (4) considerations of post-survival quality of life balanced with the family's goals of care. These decisions must often be made in the absence of complete data. Ultimately, the goals for ECMO support and criteria for separation from ECMO are best outlined before cannulation. Common understanding of and consensus on these goals and criteria should be sought among the medical, surgical, and ECMO teams and the patient's surrogate decision makers. This multi-professional approach with family engagement and investment is crucial in attempting to avoid situations where ECMO becomes the end state rather than its intended role as a transitional supportive treatment.

Fundamentally, ECMO is a temporary therapy to provide cardiopulmonary support for a finite period of time while both minimizing complications from non-ECMO and ECMO therapies and maximizing the positive effects of concurrent ongoing definitive treatments. To determine the suitability of ECMO support, pediatric critical care practitioners must answer the question: Is ECMO a bridge to decision, recovery, or transplant, or is ECMO a bridge to nowhere? As new technologies and approaches to management of pediatric respiratory failure and ECMO offer improved risk/benefit ratios, this fundamental question will need to be analyzed and studied in a rigorous fashion. Existing international databases, such as the ELSO registry, provide a tremendous resource in retrospective understanding of current state of practice and have provided insight into future questions. However, these same databases carry significant limitations to robust investigation into the subtleties inherent in the progression and management of pediatric respiratory failure. They do not include much of the granular clinical details needed to provide a robust analysis of factors associated with positive outcome. As importantly, formal assessments of long-term quality of life and functional outcomes are needed to further clarify the long-term morbidities associated with ECMO. Only through more detailed data collection and subsequent analysis can clinical research protocols be completed that will allow the family-centered multi-professional medical team to attempt to answer the pressing question: If ECMO can save my child's life, will he/she survive in a clinical condition that allows an acceptable quality of life for both my child and myself?

\section{REFERENCES}

1. Hill JD, O'Brien TG, Murray JJ, Dontigny L, Bramson ML, Osborn JJ, Gerbode F. Prolonged extracorporeal oxygenation for acute posttraumatic respiratory failure (shock-lung syndrome): use of the Bramson membrane lung. N Engl J Med 1972;286(12):629-634.

2. Hill JD, Rodvien R, Snider MT, Bartlett RH. Clinical extracorporeal membrane oxygenation for acute respiratory insufficiency. Trans Am Soc Artif Intern Organs 1978;24:753-763.

3. Bartlett RH, Gazzaniga AB, Fong SW, Jefferies MR, Roohk HV, Haiduc N. Extracorporeal membrane oxygenator support for cardiopulmonary failure. Experience in 28 cases. J Thorac Cardiovasc Surg 1977;73(3):375-386.

4. Bartlett RH, Gazzaniga AB, Huxtable RF, Schippers HC, O'Connor MJ, Jefferies MR. Extracorporeal circulation (ECMO) in neonatal respiratory failure. J Thorac Cardiovasc Surg 1977;74(6):826-833.

5. Bartlett RH, Roloff DW, Cornell RG, Andrews AF, Dillon PW, Zwischenberger JB. Extracorporeal circulation in neonatal respiratory failure: a prospective randomized study. Pediatrics 1985;76(4): 479-487.

6. O'Rourke PP, Crone RK, Vacanti JP, Ware JH, Lillehei CW, Parad RB, Epstein MF. Extracorporeal membrane oxygenation and conventional medical therapy in neonates with persistent pulmonary hypertension of the newborn: a prospective randomized study. Pediatrics 1989;84(6):957-963.

7. UK Collaborative ECMO Trial Group. UK collaborative randomised trial of neonatal extracorporeal membrane oxygenation. Lancet 1996; 348(9020):75-82.

8. Bennett CC, Johnson A, Field DJ, Elbourne D, UK Collaborative ECMO Trial Group. UK collaborative randomised trial of neonatal extracorporeal membrane oxygenation: follow-up to age 4 years. Lancet 2001;357(9262):1094-1096.

9. McNally H, Bennett CC, Elbourne D, Field DJ, UK Collaborative ECMO Trial Group. United Kingdom collaborative randomized 


\section{ECMO for Severe Pediatric Respiratory Failure}

trial of neonatal extracorporeal membrane oxygenation: follow-up to age 7 years. Pediatrics 2006;117(5):e845-e854.

10. Mugford M, Elbourne D, Field D. Extracorporeal membrane oxygenation for severe respiratory failure in newborn infants. Cochrane Database Syst Rev 2008;(3):CD001340.

11. Hui TT, Danielson PD, Anderson KD, Stein JE. The impact of changing neonatal respiratory management on extracorporeal membrane oxygenation utilization. J Pediatr Surg 2002;37(5):703-705.

12. Schaible T, Hermle D, Loersch F, Demirakca S, Reinshagen K, Varnholt V. A 20-year experience on neonatal extracorporeal membrane oxygenation in a referral center. Intensive Care Med 2010; 36(7):1229-1234.

13. Extracorporeal Life Support Organization, Ann Arbor, MI. International ECLS Registry Report, January 2017.

14. Zapol WM, Snider MT, Hill JD, Fallat RJ, Bartlett RH, Edmunds $\mathrm{LH}$, et al. Extracorporeal membrane oxygenation in severe acute respiratory failure: a randomized prospective study. JAMA 1979; 242(20):2193-2196.

15. Morris AH, Wallace CJ, Menlove RL, Clemmer TP, Orme JF Jr, Weaver LK, et al. Randomized clinical trial of pressure-controlled inverse ratio ventilation and extracorporeal $\mathrm{CO}_{2}$ removal for adult respiratory distress syndrome. Am J Respir Crit Care Med 1994; 149(2 Pt 1):295-305.

16. Peek GJ, Mugford M, Tiruvoipati R, Wilson A, Allen E, Thalanany $\mathrm{MM}$, et al. Efficacy and economic assessment of conventional ventilatory support versus extracorporeal membrane oxygenation for severe adult respiratory failure (CESAR): a multicentre randomised controlled trial. Lancet 2009;374(9698):1351-1363.

17. Zwischenberger JB, Lynch JE. Will CESAR answer the adult ECMO debate? Lancet 2009;374(9698):1307-1308.

18. Green TP, Timmons OD, Fackler JC, Moler FW, Thompson AE, Sweeney MF. The impact of extracorporeal membrane oxygenation on survival in pediatric patients with acute respiratory failure. Pediatric Critical Care Study Group. Crit Care Med 1996;24(2):323329.

19. Dalton HJ, Macrae DJ, Pediatric Acute Lung Injury Consensus Conference Group. Extracorporeal support in children with pediatric acute respiratory distress syndrome: proceedings from the Pediatric Acute Lung Injury Consensus Conference. Pediatr Crit Care Med 2015;16(5 Suppl 1):S111-S117.

20. Squiers JJ, Lima B, DiMaio JM. Contemporary extracorporeal membrane oxygenation therapy in adults: fundamental principles and systematic review of the evidence. J Thorac Cardiovasc Surg 2016; 152(1):20-32.

21. Mok YH, Lee JH, Cheifetz IM. Neonatal extracorporeal membrane oxygenation: update on management strategies and long-term outcomes. Adv Neonatal Care 2016;16(1):26-36.

22. Khemani RG, Smith LS, Zimmerman JJ, Erickson S, Pediatric Acute Lung Injury Consensus Conference Group. Pediatric acute respiratory distress syndrome: definition, incidence, and epidemiology: proceedings from the Pediatric Acute Lung Injury Consensus Conference. Pediatr Crit Care Med 2015;16(5 Suppl 1):S23-S40.

23. Bernard GR, Artigas A, Brigham KL, Carlet J, Falke K, Hudson L, et al. The American-European Consensus Conference on ARDS: definitions, mechanisms, relevant outcomes, and clinical trial coordination. Am J Respir Crit Care Med 1994;149(3 Pt 1):818-824.

24. ARDS Definition Task Force, Ranieri VM, Rubenfeld GD, Thompson BT, Ferguson ND, Caldwell E, et al. Acute respiratory distress syndrome: the Berlin definition. JAMA 2012;307(23):2526-2533.

25. Khemani RG, Patel NR, Bart RD 3rd, Newth CJ. Comparison of the pulse oximetric saturation/fraction of inspired oxygen ratio and the $\mathrm{P}_{\mathrm{aO}_{2}}$ /fraction of inspired oxygen ratio in children. Chest 2009;135(3): 662-668.
26. Khemani RG, Thomas NJ, Venkatachalam V, Scimeme JP, Berutti $\mathrm{T}$, Schneider JB, et al. Comparison of $\mathrm{S}_{\mathrm{pO}_{2}}$ to $\mathrm{P}_{\mathrm{aO}}$-based markers of lung disease severity for children with acute lung injury. Crit Care Med 2012;40(4):1309-1316.

27. Thomas NJ, Shaffer ML, Willson DF, Shih MC, Curley MA. Defining acute lung disease in children with the oxygenation saturation index. Pediatr Crit Care Med 2010;11(1):12-17.

28. Erickson S, Schibler A, Numa A, Nuthall G, Yung M, Pascoe E, et al. Acute lung injury in pediatric intensive care in Australia and New Zealand: a prospective, multicenter, observational study. Pediatr Crit Care Med 2007;8(4):317-323.

29. Flori H, Dahmer MK, Sapru A, Quasney MW. Pediatric Acute Lung Injury Consensus Conference Group. Comorbidities and assessment of severity of pediatric acute respiratory distress syndrome: proceedings from the Pediatric Acute Lung Injury Consensus Conference. Pediatr Crit Care Med 2015;16(5 Suppl 1): S41-S50.

30. Timmons OD, Havens PL, Fackler JC. Predicting death in pediatric patients with acute respiratory failure: Pediatric Critical Care Study Group: Extracorporeal Life Support Organization. Chest 1995; 108(3):789-797.

31. Paret G, Ziv T, Barzilai A, Ben-Abraham R, Vardi A, Manisterski Y, Barzilay Z. Ventilation index and outcome in children with acute respiratory distress syndrome. Pediatr Pulmonol 1998;26(2):125128.

32. Ghuman AK, Newth CJ, Khemani RG. The association between the end tidal alveolar dead space fraction and mortality in pediatric acute hypoxemic respiratory failure. Pediatr Crit Care Med 2012; 13(1):11-15.

33. Khemani RG, Conti D, Alonzo TA, Bart RD 3rd, Newth CJ. Effect of tidal volume in children with acute hypoxemic respiratory failure. Intensive Care Med 2009;35(8):1428-1437.

34. Gupta M, Shanley TP, Moler FW. Extracorporeal life support for severe respiratory failure in children with immune compromised conditions. Pediatr Crit Care Med 2008;9(4):380-385.

35. Di Nardo M, Locatelli F, Palmer K, Amodeo A, Lorusso R, Belliato $\mathrm{M}$, et al. Extracorporeal membrane oxygenation in pediatric recipients of hematopoietic stem cell transplantation: an updated analysis of the Extracorporeal Life Support Organization experience. Intensive Care Med 2014;40(5):754-756.

36. Gupta P, Carlson J, Wells D, Selakovich P, Robertson MJ, Gossett $\mathrm{JM}$, et al. Relationship between renal function and extracorporeal membrane oxygenation use: a single-center experience. Artif Organs 2015;39(4):369-374.

37. Lyu L, Long C, Hei F, Ji B, Liu J, Yu K, et al. Plasma free hemoglobin is a predictor of acute renal failure during adult venous-arterial extracorporeal membrane oxygenation support. J Cardiothorac Vasc Anesth 2016;30(4):891-895.

38. Villa G, Katz N, Ronco C. Extracorporeal membrane oxygenation and the kidney. Cardiorenal Med 2015;6(1):50-60.

39. Askenazi DJ, Ambalavanan N, Hamilton K, Cutter G, Laney D, Kaslow R, et al. Acute kidney injury and renal replacement therapy independently predict mortality in neonatal and pediatric noncardiac patients on extracorporeal membrane oxygenation. Pediatr Crit Care Med 2011;12(1):e1-e6.

40. Lou S, MacLaren G, Paul E, Best D, Delzoppo C, Butt W. Hemofiltration is not associated with increased mortality in children receiving extracorporeal membrane oxygenation. Pediatr Crit Care Med 2015;16(2):161-166.

41. Bailly DK, Bratton SL. Extracorporeal membrane oxygenation, dialysis, and mortality: let's agree to agree. Pediatr Crit Care Med 2015;16(2):192-193. 


\section{ECMO for Severe Pediatric Respiratory Failure}

42. Moler FW, Palmisano J, Custer JR. Extracorporeal life support for pediatric respiratory failure: predictors of survival from 220 patients. Crit Care Med 1993;21(10):1604-1611.

43. Moler FW, Palmisano JM, Green TP, Custer JR. Predictors of outcome of severe respiratory syncytial virus-associated respiratory failure treated with extracorporeal membrane oxygenation. J Pediatr 1993;123(1):46-52.

44. Domico MB, Ridout DA, Bronicki R, Anas NG, Cleary JP, Cappon $\mathrm{J}$, et al. The impact of mechanical ventilation time before initiation of extracorporeal life support on survival in pediatric respiratory failure: a review of the Extracorporeal Life Support Registry. Pediatr Crit Care Med 2012;13(1):16-21.

45. Ahmad SB, Menaker J, Kufera J, O'Connor J, Scalea TM, Stein DM. Extracorporeal membrane oxygenation after traumatic injury. J Trauma Acute Care Surg 2017;82(3):587-591.

46. MacLaren G, Butt W, Best D, Donath S. Central extracorporeal membrane oxygenation for refractory pediatric septic shock. Pediatr Crit Care Med 2011;12(2):133-136.

47. Kimura D, Shah S, Briceno-Medina M, Sathanandam S, Haberman B, Zhang J, et al. Management of massive diffuse alveolar hemorrhage in a child with systemic lupus erythematosus. J Intensive Care 2015;3:10.

48. Rawal G, Kumar R, Yadav S. ECMO rescue therapy in diffuse alveolar haemorrhage: a case report with review of literature. J Clin Diagn Res 2016;10(6):OD10-OD11.

49. Glass P, Wagner AE, Papero PH, Rajasingham SR, Civitello LA, Kjaer MS, et al. Neurodevelopmental status at age five years of neonates treated with extracorporeal membrane oxygenation. J Pediatr 1995;127(3):447-457.

50. Jen HC, Shew SB. Hospital readmissions and survival after nonneonatal pediatric ECMO. Pediatrics 2010;125(6):1217-1223.

51. Maclaren G, Butt W, Best D, Donath S, Taylor A. Extracorporeal membrane oxygenation for refractory septic shock in children: one institution's experience. Pediatr Crit Care Med 2007;8(5):447-451.

52. Taylor AK, Cousins R, Butt WW. The long-term outcome of children managed with extracorporeal life support: an institutional experience. Crit Care Resusc 2007;9(2):172-177.

53. Chandler HK, Teppa B, Johnson KA, McCracken C, Fortenberry JD, Paden ML. Determining comorbidities and quality of life among pediatric survivors of extracorporeal life support. J Crit Care 2015; 30(5):1085-1089.

54. Stroud MH, Okhuysen-Cawley R, Jaquiss R, Berlinski A, Fiser RT. Successful use of extracorporeal membrane oxygenation in severe necrotizing pneumonia caused by Staphylococcus aureus. Pediatr Crit Care Med 2007;8(3):282-287.

55. Veith FJ. Lung transplantation. Transplant Proc 1977;9(1):203-208.

56. Jackson A, Cropper J, Pye R, Junius F, Malouf M, Glanville A. Use of extracorporeal membrane oxygenation as a bridge to primary lung transplant: 3 consecutive, successful cases and a review of the literature. J Heart Lung Transplant 2008;27(3):348-352.

57. Jurmann MJ, Schaefers HJ, Demertzis S, Haverich A, Wahlers T, Borst HG. Emergency lung transplantation after extracorporeal membrane oxygenation. ASAIO J 1993;39(3):M448-M452.

58. American Society for Transplant Physicians (ASTP)/American Thoracic Society (ATS)/European Respiratory Society (ERS)/International Society for Heart and Lung Transplantation (ISHLT). International guidelines for the selection of lung transplant candidates. Am J Respir Crit Care Med 1998;158(1):335-339.

59. Mason DP, Thuita L, Nowicki ER, Murthy SC, Pettersson GB, Blackstone EH. Should lung transplantation be performed for patients on mechanical respiratory support? the US experience. J Thorac Cardiovasc Surg 2010;139(3):765-773.e1.
60. Diaz-Guzman E, Hoopes CW, Zwischenberger JB. The evolution of extracorporeal life support as a bridge to lung transplantation. ASAIO J 2013;59(1):3-10.

61. Nosotti M, Rosso L, Tosi D, Palleschi A, Mendogni P, Nataloni IF, et al. Extracorporeal membrane oxygenation with spontaneous breathing as a bridge to lung transplantation. Interact Cardiovasc Thorac Surg 2013;16(1):55-59.

62. Schechter MA, Ganapathi AM, Englum BR, Speicher PJ, Daneshmand MA, Davis RD, Hartwig MG. Spontaneously breathing extracorporeal membrane oxygenation support provides the optimal bridge to lung transplantation. Transplantation 2016;100(12):26992704.

63. Crotti S, Iotti GA, Lissoni A, Belliato M, Zanierato M, Chierichetti $\mathrm{M}$, et al. Organ allocation waiting time during extracorporeal bridge to lung transplant affects outcomes. Chest 2013;144(3):1018-1025.

64. Chiumello D, Coppola S, Froio S, Colombo A, Del Sorbo L. Extracorporeal life support as bridge to lung transplantation: a systematic review. Crit Care 2015;19:19.

65. Casswell GK, Pilcher DV, Martin RS, Pellegrino VA, Marasco SF, Robertson C, et al. Buying time: The use of extracorporeal membrane oxygenation as a bridge to lung transplantation in pediatric patients. Pediatr Transplant 2013;17(8):E182-E188.

66. Hayes D Jr, McConnell PI, Tobias JD, Whitson BA, Preston TJ, Yates AR, Galantowicz M. Survival in children on extracorporeal membrane oxygenation at the time of lung transplantation. Pediatr Transplant 2015;19(1):87-93.

67. Schmid FA, Inci I, Bürgi U, Hillinger S, Schneiter D, Opitz I, et al. Favorable outcome of children and adolescents undergoing lung transplantation at a European adult center in the new era. Pediatr Pulmonol 2016;51(11):1222-1228.

68. Puri V, Epstein D, Raithel SC, Gandhi SK, Sweet SC, Faro A, Huddleston CB. Extracorporeal membrane oxygenation in pediatric lung transplantation. J Thorac Cardiovasc Surg 2010;140(2):427432.

69. Turner DA, Cheifetz IM, Rehder KJ, Williford WL, Bonadonna D, Banuelos SJ, et al. Active rehabilitation and physical therapy during extracorporeal membrane oxygenation while awaiting lung transplantation: a practical approach. Crit Care Med 2011;39(12):25932598 .

70. Schmidt F, Sasse M, Boehne M, Mueller C, Bertram H, Kuehn C, et al. Concept of "awake venovenous extracorporeal membrane oxygenation" in pediatric patients awaiting lung transplantation. Pediatr Transplant 2013;17(3):224-230.

71. Rehder KJ, Turner DA, Hartwig MG, Williford WL, Bonadonna D, Walczak RJ Jr, et al. Active rehabilitation during extracorporeal membrane oxygenation as a bridge to lung transplantation. Respir Care 2013;58(8):1291-1298.

72. Hayes D Jr, Lloyd EA, Yates AR, McConnell PI, Galantowicz M, Preston TJ. Pediatric ambulatory ECMO. Lung 2014;192(6):1005.

73. Hayes D Jr, Galantowicz M, Preston TJ, Lloyd EA, Tobias JD, McConnell PI. Tracheostomy in adolescent patients bridged to lung transplantation with ambulatory venovenous extracorporeal membrane oxygenation. J Artif Organs 2014;17(1):103-105.

74. Wong JY, Buchholz H, Ryerson L, Conradi A, Adatia I, Dyck J, et al. Successful semi-ambulatory veno-arterial extracorporeal membrane oxygenation bridge to heart-lung transplantation in a very small child. Am J Transplant 2015;15(8):2256-2260.

75. Zabrocki LA, Brogan TV, Statler KD, Poss WB, Rollins MD, Bratton SL. Extracorporeal membrane oxygenation for pediatric respiratory failure: survival and predictors of mortality. Crit Care Med 2011;39(2):364-370.

76. Newth CJ, Meert KL, Clark AE, Moler FW, Zuppa AF, Berg RA, et al. Fatal and near-fatal asthma in children: the critical care perspective. J Pediatr 2012;161(2):214-221.e3. 


\section{ECMO for Severe Pediatric Respiratory Failure}

77. Hebbar KB, Petrillo-Albarano T, Coto-Puckett W, Heard M, Rycus PT, Fortenberry JD. Experience with use of extracorporeal life support for severe refractory status asthmaticus in children. Crit Care 2009;13(2):R29.

78. de Lange DW, Sikma MA, Meulenbelt J. Extracorporeal membrane oxygenation in the treatment of poisoned patients. Clin Toxicol (Phila) 2013;51(5):385-393.

79. Teerapuncharoen K, Sharma NS, Barker AB, Wille KM, DiazGuzman E. Successful treatment of severe carbon monoxide poisoning and refractory shock using extracorporeal membrane oxygenation. Respir Care 2015;60(9):e155-e160.

80. Willms DC, Mendez R, Norman V, Chammas JH. Emergency bedside extracorporeal membrane oxygenation for rescue of acute tracheal obstruction. Respir Care 2012;57(4):646-649.

81. Cornish JD, Carter JM, Gerstmann DR, Null DM Jr. Extracorporeal membrane oxygenation as a means of stabilizing and transporting high risk neonates. ASAIO Trans 1991;37(4):564-568.

82. Coppola CP, Tyree M, Larry K, DiGeronimo R. A 22-year experience in global transport extracorporeal membrane oxygenation. J Pediatr Surg 2008;43(1):46-52; discussion 52.

83. Lindén V, Palmér K, Reinhard J, Westman R, Ehrén H, Granholm T, Frenckner B. Inter-hospital transportation of patients with severe acute respiratory failure on extracorporeal membrane oxygenation: national and international experience. Intensive Care Med 2001; 27(10):1643-1648

84. Foley DS, Pranikoff T, Younger JG, Swaniker F, Hemmila MR, Remenapp RA, et al. A review of 100 patients transported on extracorporeal life support. ASAIO J 2002;48(6):612-619.

85. Clement KC, Fiser RT, Fiser WP, Chipman CW, Taylor BJ, Heulitt MJ, et al. Single-institution experience with interhospital extracorporeal membrane oxygenation transport: a descriptive study. Pediatr Crit Care Med 2010;11(4):509-513.

86. Broman LM, Holzgraefe B, Palmér K, Frenckner B. The Stockholm experience: interhospital transports on extracorporeal membrane oxygenation. Crit Care 2015;19:278.

87. Nwozuzu A, Fontes ML, Schonberger RB. Mobile extracorporeal membrane oxygenation teams: the North American versus the European experience. J Cardiothorac Vasc Anesth 2016;30(6):14411448.

88. Brogan TV, Thiagarajan RR, Rycus PT, Bartlett RH, Bratton SL. Extracorporeal membrane oxygenation in adults with severe respiratory failure: a multi-center database. Intensive Care Med 2009; 35(12):2105-2114.

89. Schmidt M, Pellegrino V, Combes A, Scheinkestel C, Cooper DJ, Hodgson C. Mechanical ventilation during extracorporeal membrane oxygenation. Crit Care 2014;18(1):203.

90. Schmidt M, Stewart C, Bailey M, Nieszkowska A, Kelly J, Murphy $\mathrm{L}$, et al. Mechanical ventilation management during extracorporeal membrane oxygenation for acute respiratory distress syndrome: a retrospective international multicenter study. Crit Care Med 2015; 43(3):654-664.

91. Marhong JD, Telesnicki T, Munshi L, Del Sorbo L, Detsky M, Fan E. Mechanical ventilation during extracorporeal membrane oxygenation. an international survey. Ann Am Thorac Soc 2014;11(6): 956-961.

92. Yehya N, Dominick CL, Connelly JT, Davis DH, Minneci PC, Deans KJ, et al. High-frequency percussive ventilation and bronchoscopy during extracorporeal life support in children. ASAIO J 2014;60(4):424-428.

93. Rizkalla NA, Dominick CL, Fitzgerald JC, Thomas NJ, Yehya N. High-frequency percussive ventilation improves oxygenation and ventilation in pediatric patients with acute respiratory failure. J Crit Care 2014;29(2):314.e1-7.

94. Wickiser JE, Thompson M, Leavey PJ, Quinn CT, Garcia NM, Aquino VM. Extracorporeal membrane oxygenation (ECMO) initiation without intubation in two children with mediastinal malignancy. Pediatr Blood Cancer 2007;49(5):751-754.

95. Collar RM, Taylor JC, Hogikyan ND, Tutuo N, Ohye RG, Green GE. Awake extracorporeal membrane oxygenation for management of critical distal tracheal obstruction. Otolaryngol Head Neck Surg 2010;142(4):618-620

96. Rake J, Johnson B, Seger B, Manning PB, Eghtesady P, Boesch P, et al. Extracorporeal membrane oxygenation, extubation, and lungrecruitment maneuvers as rescue therapy in a patient with tracheal dehiscence following slide tracheoplasty. Respir Care 2011;56(8): 1198-1202.

97. Anton-Martin P, Thompson MT, Sheeran PD, Fischer AC, Taylor D, Thomas JA. Extubation during pediatric extracorporeal membrane oxygenation: a single-center experience. Pediatr Crit Care Med 2014;15(9):861-869.

98. Di Nardo M, Pirozzi N, Pesenti A. Extubation during pediatric extracorporeal membrane oxygenation: is it always safe? Pediatr Crit Care Med 2015;16(5):493-494.

99. Brochard L, Slutsky A, Pesenti A. Mechanical ventilation to minimize progression of lung injury in acute respiratory failure. Am J Respir Crit Care Med 2017;195(4):438-442.

100. Dalton HJ. ECMO for pediatric respiratory failure. In: Annich GM, editor. ECMO: extracorporeal cardiopulmonary support in critical care. Ann Arbor, Michigan: Extracorporeal Life Support Organization; 2012:265-291.

101. Koogler TK. ECMO ethics in the twenty-first century. In: Annich GM, editor. ECMO: extracorporeal cardiopulmonary support in critical care. Ann Arbor, Michigan: Extracorporeal Life Support Organization; 2012:527-534.

102. Hurst JM, Branson RD, Davis K Jr. High-frequency percussive ventilation in the management of elevated intracranial pressure. J Trauma 1988;28(9):1363-1367.

103. Cioffi WG, Graves TA, McManus WF, Pruitt BA Jr. High-frequency percussive ventilation in patients with inhalation injury. J Trauma 1989;29(3):350-354.

104. Cortiella J, Mlcak R, Herndon D. High frequency percussive ventilation in pediatric patients with inhalation injury. J Burn Care Rehabil 1999;20(3):232-235.

105. Kopp R, Dembinski R, Kuhlen R. Role of extracorporeal lung assist in the treatment of acute respiratory failure. Minerva Anestesiol 2006;72(6):587-595.

106. Hoganson DM, Gazit AZ, Sweet SC, Grady RM, Huddleston CB, Eghtesady P. Neonatal paracorporeal lung assist device for respiratory failure. Ann Thorac Surg 2013;95(2):692-694.

107. Boston US, Fehr J, Gazit AZ, Eghtesady P. Paracorporeal lung assist device: an innovative surgical strategy for bridging to lung transplant in an infant with severe pulmonary hypertension caused by alveolar capillary dysplasia. J Thorac Cardiovasc Surg 2013; 146(4):e42-e43.

108. Gazit AZ, Sweet SC, Grady RM, Huddleston CB. First experience with a paracorporeal artificial lung in a small child with pulmonary hypertension. J Thorac Cardiovasc Surg 2011;141(6):e48-e50.

109. Gazit AZ, Sweet SC, Grady RM, Boston US, Huddleston CB, Hoganson DM, et al. Recommendations for utilization of the paracorporeal lung assist device in neonates and young children with pulmonary hypertension. Pediatr Transplant 2016;20(2):256-270 


\section{Discussion}

Kuch: John, nice talk. I think it's really interesting, and I'm glad you broached the topic of the open lung versus complete lung rest. The data you showed demonstrating improved outcome from increased PEEP applied during the ECMO run suggests that these patients have lungs that are more prone to collapse. Using adequate PEEP helps keep the lung open, allowing us to protect the lung, and decreases the risk of total collapse, which is difficult to recruit. I think it's something that needs to be addressed because an open lung seems to help separate from ECMO earlier. The second part of that is how do you feel about volume status with these patients? There are some theories out there that look at running these patients at an even volume status, but what happens is we're often getting well behind, and they are grossly volume-overloaded, which adds a whole list of issues. Do you think there's any value in investigating that area, in terms of running them neutral versus drying them out with renal perfusion and urine output?

Lin: I think that's an excellent point. There was a paper by Selewski et al ${ }^{1}$ that demonstrated that percent volume overload prior to initiation of continuous renal replacement therapy (CRRT) in pediatric ECMO subjects correlated with mortality: $24.5 \%$ versus $38 \%$ fluid overload in survivors compared to non-survivors. Whether using some form of CRRT to manage that volume status and whether that improves ECMO outcome remains unclear. I think that in order to achieve a lung recruitment strategy and not use the same ventilator settings that you were on before you even went on ECMO, you have to keep the lungs relatively fluid-neutral. Whether that's best achieved with diuretics or CRRT is unknown.

Sweet: Nice talk. The data about preECMO mechanical ventilation suggest that the longer you're on the vent, the worse off you're going to be. Do you have a sense of what the etiology of that is? Is it just a cumulative lung injury where you aren't going to recover, or is there something else?

Lin: I think this really goes to the heart of the question Ira [Cheifetz] began to pose: When is the optimal time to put somebody on ECMO? Is it $2 \mathrm{~d}$ into their respiratory failure and it doesn't seem like they're getting better, is it $7 \mathrm{~d}$, or is it somewhere in between? We know that any amount of positive-pressure ventilation can initiate ventilator-induced lung injury and a subsequent inflammatory response. These are also the patients who are not undergoing aggressive early mobilization. The adult literature is replete with the success of a coordinated approach to pain, sedation, and delirium management; daily spontaneous awakening and breathing trials; and early mobilization at improving ventilator-free days in adult patients with ARDS. A multidiscliplinary approach and emphasis on this from day 1 after the patient is intubated leads to shorter mechanical ventilation duration, shorter ICU length of stay, and improved longterm recovery. Is this feasible in children? The literature is building with pediatric case reports describing older children undergoing ambulatory ECMO without complication. How to best select suitable pediatric patients, how to modify the adult approach to best address the neurocognitive differences between children and adults and among children at different developmental stages, what resources are necessary to perform ambulatory ECMO safely - these questions and more have not been answered.

Cheifetz: Thank you, John. You presented excellent data regarding ECMO, duration of ventilation, and pre-transplant outcomes. The point in my presentation was exactly what you are saying. I believe the key issue is not so much the duration of ventila- tion or what you do to the lungs pretransplant (as they will be removed), it is what you said, whether the patient is awake and moving or sedated in bed. We discharged an adolescent to home $14 \mathrm{~d}$ after a bilateral lung transplant largely because she went into her transplant in amazing physical shape. This is not an isolated event; I really believe that lung transplant outcomes are greatly influenced by mobility and the physical conditioning of the patient as they enter the operating room.

Lin: I totally agree.

Sweet: We are really loath to trach kids who have significant lung injury. And I suspect tracheostomies are a significant component in the ability to ambulate. Is that another area where we need to be talking about how we approach these kids with severe lung injury?

Lin: Absolutely. The adult approach is you get intubated, and Rich [Branson] could tell us that it's the rare patient he takes care of in the adult side who is on a vent for much more than $3 \mathrm{~d}$ with no expectation of coming off in the next day or so who doesn't already have a trach in place.

Rehder: I agree with the trach comments. On a separate note, you talked about the need to select the right patient, particularly with those who may go on to transplant. Our experience has demonstrated that many of the patients who do go on to transplant had acute kidney injury at the time they went onto ECMO. It was not associated with ECMO; it was pre-ECMO because of their state when they came in. So, it adds to the challenge of trying to guess about the reversibility of lung injury because we have had a couple along the way who never did regain that kidney function, and this contributed to poor outcomes, but if we had excluded them at the outset for kidney injury, there were also 
several who survived transplant and did well who would not have been included. Ira's favorite phrase for this is the "bridge to decision," which I think sometimes is what we have to do. But how do you identify those patients as early as possible, to optimize not only outcomes, but also resource utilization?

Lin: You bring up a really good point, which is when you don't have all the data you need at the beginning, is this patient still really a transplant candidate? Does this patient truly have irreversible lung or other organ injury? For example, the patient with cystic fibrosis who presents with acute-onchronic respiratory failure from a concurrent respiratory infection or the patient who has decreased urine output but whose creatinine has not increased and has not yet met pRIFLE (pediatric risk, injury, failure, loss, end-stage renal disease) criteria for acute kidney injury but who is developing worsening fluid overload with suspected renal injury - it would be challenging to predict the clinical trajectory at the time that decision-making regarding ECMO initiation occurs. ECMO as a bridge to decision is certainly a valid approach, but that implies that everybody will be on the same page when that decision needs to be made. If preset criteria for decision-making have not been agreed upon, ECMO may become the destination, rather than only the bridge. I also believe that there's a deficit in the way we approach assent versus consent in the pediatric world. Advance directives in previously healthy children are rare. The last thing any parent has ever thought about is what would their child want if they were dying? It's an ethical question. The second-to-last chapter in the latest edition of the ECMO Red Book is devoted to ethical considerations in ECMO management. And there's no good answer. We don't tell families we're not going to give their child ECMO, we only tell them, "We have this modality that may save your kid's life but will not cure their underlying disease and carries many life-threatening complications. Do you want us to try?" and all they hear is, "Maybe you're going to save my kid's life." Not that they might bleed, or they might suffer a devastating neurologic injury, or they may have profound morbidities even if they survive.

Stokes: I was interested in your comments about bone marrow transplant and the futility of ECMO. I'm not sure there are enough data to say, for other populations of immunocompromised and cancer patients, whether ECMO outcomes are equally dismal. Do you have any comments about that population?

Lin: I didn't present those data here, but in that original series, no transplant patients survived. Since that time, about $25-50 \%$ of the patients who have had bone marrow transplant resulting in ARDS who went on ECMO survived. Now, we're talking about fewer than 10 patients, of whom then 3 or 4 survived. The other immunodeficiencies then, there are some more recent data about malignancies in general, non-transplant, that suggest their outcome post-ECMO is not that far off from patients who don't have those premorbid conditions. I don't know off the top of my head what those percentages are; it's not as good as not having it, but it's not quite as bad as the slide that I showed.

Cheifetz: I am concerned about the comment you just made about 25-50\% of bone marrow transplant patients managed with ECMO now surviving...

Lin: Like I said, you're talking about 10 patients.

Cheifetz: OK, but just to be clear, clinicians generally do not report their failures. We did an informal survey among the stem-cell transplant group of PALISI, and the ECMO survival rate for stem-cell transplant patients was single digits. The outcomes are dismal. In terms of the few reports on this topic, we must remember the denominator is not being fully reported. The other follow-up point I will make is in regard to ambulating younger children. Most of the photographs I show from Duke are of adolescents because we are an adolescent lung transplant program, not a pediatric lung transplant program. However, as a bridge to recovery, the youngest patient we managed was $7 \mathrm{y}$ old, and she was on ECMO for about 2 months. Unfortunately, she was not able to ambulate because she was cannulated via her femoral vein at another institution. However, she was fully awake, interactive, and completely cooperative. In the 2 months on ECMO, there was never even a hint that she would be a danger to her life-support apparatus. Obviously, it is child-dependent. There are uncooperative teenagers and very cooperative children; it is really caseby-case, but I know that other lung transplant centers have walked pediatric-age ECMO patients.

Lin: Nationwide, Children's Hospital reported an 8-y-old successfully bridged to recovery using ambulatory VV-ECMO and provided a photograph of the child riding a tricycle with VVECMO cannula in place in his neck. ${ }^{2}$ So, it's clearly possible; it's very dependent on the circumstances of the child, the way that child interacts with the medical team, and the family who are present and their ability to assist. It's not just saying "We're going to do this," and it happens. It's "We're going to do this, and we need cooperation from the entire interdisciplinary team, the family, and the patient."

Walsh: I'd like to ask one last question because a lot of the readers are going to be respiratory therapists, and we're often left with what do you do with the lungs after you put them on ECMO? One of the things I've seen over the years is 10-10-10 (frequency 
of $10,10 \mathrm{~cm} \mathrm{H}_{2} \mathrm{O}$ of PEEP, and pressure control of 10) came from our days of neonatal ECMO and largely using VA-ECMO, where you could basically forget the lungs and not have to worry about it. This has changed now that we use much more VV-ECMO and we can't forget the lungs; the patient will not allow you to. So then we're left with, "What do you do?" and I see strategies all the way from extubation and ambulating to 15 of PEEP and $\Delta<10$. What do you suggest we do, and how do you target rest settings, which, by the way, I don't believe rest the lungs. Even atelectasis is not rest a lot of the time, so how do you balance everything from overdistention or barotrauma or volutrauma to atelectatic trauma?

Lin: That is the million dollar question in this particular area. What is the optimal ventilator management while receiving VV-ECMO? Insufficient ventilator pressures to maintain a threshold functional residual capacity will increase pulmonary vascular resistance and may contribute to poorly tolerated right-heart dysfunction. My own personal practice is that on VVECMO I never let the lungs collapse. I also never let the lungs fully collapse on VA-ECMO, although I'm likely to allow the lungs to be a little less inflated on VA-ECMO because the artificial right to left shunt may be sufficient to unload the right ventricle by bypassing the pulmonary vascular bed. This external shunt allows me to be more protective with ventilator pressures. A lot of that is patientdependent and what's going on with that patient, what direction do we think this kid is going, what is the underlying issue? An immunocompromised patient with adenoviremia, adenoviral pneumonia, and persistent air leak forces you to limit ventilator pressures even more stringently.

Walsh: We often run into this where we just put them on VV-ECMO and they're still requiring $80 \% \mathrm{O}_{2}$, and suddenly we say we can lower their sat range to $85 \%$, where $>90 \%$ was acceptable on conventional ventilation much less noninvasive, not circulating their blood outside their body. It's a Catch-22. We get more invasive by adding another drain to try and get flows higher so that we can get sats up so that I can rest the lungs. There's a huge debate among our folks of whether $60 \% \mathrm{O}_{2}$ still toxic, is a PIP of 30 still toxic on ECMO? You see where I am going? You now have 2 devices, and you're still not able to protect the lung. Often we can sweep off $\mathrm{CO}_{2}$ so ventilation is not as much of a problem, but oxygenation remains an issue in these difficult patients on VV-ECMO.

Lin: This question of what do you do with a patient who's on VV-ECMO whose sats are still in the mid-80s. Assuming that their sats were low before you went on ECMO, you would expect improvement after initiation of ECMO, and I'm sure you would be disappointed if that did not occur. In those situations, you would have to rule out an intracardiac shunt such, as an undiagnosed patent foramen ovale, or troubleshoot the amount of ECMO flow you were achieving and how to increase ECMO support. You also have to assess their physiologic response to hypoxemia and whether they are experiencing hypoxia. Are they developing lactic acidosis? Are they developing a venous sat to arterial sat difference $>30 \%$ ? We've had 2 or 3 cases in recent memory where we struggled to get their saturations above the high 80 s despite being on what we could achieve with VV-ECMO support. One of them was found to have a previously unrecognized patent foramen ovale. I don't have an answer for you. Toxic ventilator settings are different from person to person. In general, I try to keep the peak $\mathrm{P}_{\mathrm{aw}}$ less than 30 , ideally a good deal less than 30. I'm not quite as concerned about PEEP, per se, unless there's evidence of profound overdistention or in someone with lower airway obstructive disease, such as a patient with asthma. This patient's ventilator approach would be totally differently than someone with ARDS who's on ECMO. $\mathrm{F}_{\mathrm{IO}_{2}}$, I generally want to keep it south of 0.6 , ideally closer to 0.4 , but a lot of that is really borrowed from the neonatal and adult literature, where you try and get them on as little oxygen as possible. Everyone has to keep in mind that VV-ECMO is not going to capture all of the flow and neither is VA$\mathrm{ECMO}$, and in VV-ECMO in particular you're going to have a lot of hyperand hypo-oxygenated blood mixing as it travels through the patient's lungs. You're going to see pulmonary vein desaturation at the end of it. How we accommodate that really I think is entirely dependent on the patient's clinical status.

\section{REFERENCES}

1. Selewski DT, Cornell TT, Blatt NB, Han YY, Mottes T, Kommareddi M, et al. Fluid overload and fluid removal in pediatric patients on extracorporeal membrane oxygenation requiring continuous renal replacement therapy. Crit Care Med 2012;40(9):26942699.

2. Hayes D Jr, Lloyd EA, Yates AR, McConnell PI, Galantowicz M, Preston TJ. Pediatric ambulatory ECMO. Lung 2014;192(6): 1005-. 